BMJ Open Gastroenterology

\title{
Systematic review of genetic association studies involving histologically confirmed non-alcoholic fatty liver disease
}

\author{
Kayleigh L Wood, ${ }^{1}$ Michael H Miller, ${ }^{2}$ John F Dillon, ${ }^{2}$
}

To cite: Wood KL, Miller MH, Dillon JF. Systematic review of genetic association studies involving histologically confirmed non-alcoholic fatty liver disease. BMJ Open Gastro 2015;2:e00019. doi:10.1136/bmjgast-2014000019

- Additional material is available. To view please visit the journal (http://dx.doi.org/ 10.1136/bmjgast-2014000019).

Received 30 September 2014 Revised 21 January 2015 Accepted 23 January 2015
${ }^{1}$ School of Medicine, University of Dundee, Dundee, UK

${ }^{2}$ Medical Research Institute, University of Dundee, Ninewells Hospital, Dundee, UK

Correspondence to Dr John F Dillon; j.dillon@nhs.net

\section{ABSTRACT}

Non-alcoholic fatty liver disease has an increasing prevalence in Western countries, affecting up to $20 \%$ of the population.

Objective: The aim of this project was to systematically review and summarise the genetic association studies that investigate possible genetic influences that confer susceptibility to non-alcoholic fatty liver disease and non-alcoholic steatohepatitis.

Design: The MEDLINE and SCOPUS databases were searched to identify candidate gene studies on histologically diagnosed non-alcoholic fatty liver disease.

Results: A total of 85 articles have been summarised and categorised on the basis of the general pathway each candidate gene is involved in, including lipid metabolism, lipoprotein processing, cholesterol synthesis, glucose homoeostasis, inflammatory response, protection against oxidative stress and whole body metabolism.

Conclusions: The main findings demonstrate a small but consistent association of PNPLA3 with nonalcoholic fatty liver disease and non-alcoholic steatohepatitis. Genetic association studies have investigated general disease susceptibility, histological characteristics, severity and progression. However, further study is required to better elucidate the genetic factors influencing fatty liver disease.

\section{INTRODUCTION}

\section{Overview}

Non-alcoholic fatty liver disease (NAFLD) is an increasingly common disorder and a major global burden, affecting up to $30 \%$ of the general population and approximately $80 \%$ of obese individuals. ${ }^{1}$ NAFLD is frequently associated with the metabolic syndrome including diabetes mellitus, hypercholesterolaemia and obesity, and NAFLD can be divided into simple steatosis (SS), involving lipid accumulation in the liver, and the more severe nonalcoholic steatohepatitis (NASH), accounting for approximately $5 \%$ of UK cases. ${ }^{2}$ There are no approved treatments for NAFLD; management is exercise and weight loss. ${ }^{1}$ The mortality in NAFLD is mainly cardiovascular disease; however, NASH causes cirrhosis, end-stage liver disease and hepatocellular carcinoma (HCC). ${ }^{1}$

It has been proposed that the aetiology of NAFLD is multifactorial, involving interacting genetic and environmental factors. Studies have investigated candidate genes for susceptibility to NAFLD and to NASH. This project aimed to produce a systematic review of the candidate gene studies that investigate genetic association with histological characteristics of NAFLD and NASH.

\section{Diagnosis of NAFLD}

NAFLD is defined as "fat accumulation in the liver exceeding $5 \%$ of its weight", ${ }^{1}$ and is a diagnosis of exclusion based on clinical, biochemical and imaging techniques, although the gold standard is liver biopsy. ${ }^{1}$ Diagnosis of NASH requires liver biopsy and is based on histological criteria; there is not a universally accepted system, ${ }^{1}$ but the NAFLD-Activity Score (NAS), by Kleiner et $a l^{3}$ has been independently validated and used in research. ${ }^{1}$

\section{MATERIALS AND METHODS}

Selection criteria and search strategy

Systematic literature searches were performed in accordance with the PRISMA 2009 guidelines $^{4}$ through to 12 May 2014. The MEDLINE and SCOPUS databases were searched for studies evaluating single nucleotide polymorphisms (SNPs) for association with and/or severity of histologically diagnosed NAFLD or NASH, using keywords relating to: (1) disease (MESH "fatty liver", NASH, NAFLD) and (2) genetic studies (MESH "polymorphism, single nucleotide", 
MESH "genetic association studies", MESH "genetic predisposition to disease", polymorphism). Results were restricted to human and English language studies. Articles were screened for relevance using the title and abstract. Editorial, correspondence and review papers were excluded. Full-text articles were then obtained for the remaining studies; inclusion required histological diagnosis of NAFLD or NASH, and that fatty liver disease was distinguished from alternate causes of liver disease, including alcoholic, viral, drug-induced and autoimmune aetiologies. Histological diagnosis was used as a standard for study quality, and studies using clinical, imaging or biochemical criteria for NAFLD and NASH were not included. Results were required to be reported using ORs and CIs. A traditional, descriptive review of the literature was performed.

\section{SEARCH RESULTS}

\section{Systematic literature search}

Literature searches of MEDLINE and SCOPUS databases, through to 12 May 2014, retrieved a total of 465 articles after duplicates were removed. There were 205 articles that were not relevant candidate gene studies, and review, editorial and correspondence articles accounted for 86 papers. Of the genetic studies relating to NAFLD, diagnosis was based on MRI or CT in 25 instances, hepatic ultrasound scan in 48 , and 14 papers focused on clinical and biochemical characteristics (figure 1). Four articles were further excluded from the review: in one case, exclusion was due to inconsistency between NAFLD and NASH $;{ }^{5}$ two studies did not report results relating to individual genes; ${ }^{6} 7$ and one study did not exclude fatty liver from the control cases. ${ }^{8}$

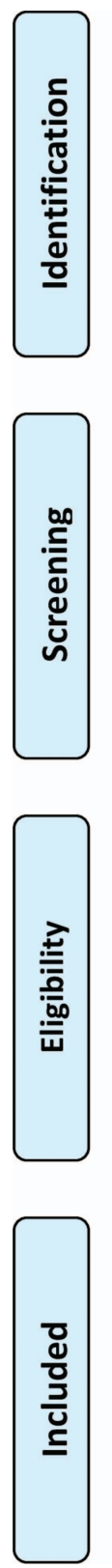

Records identified through database searching $(n=543)$
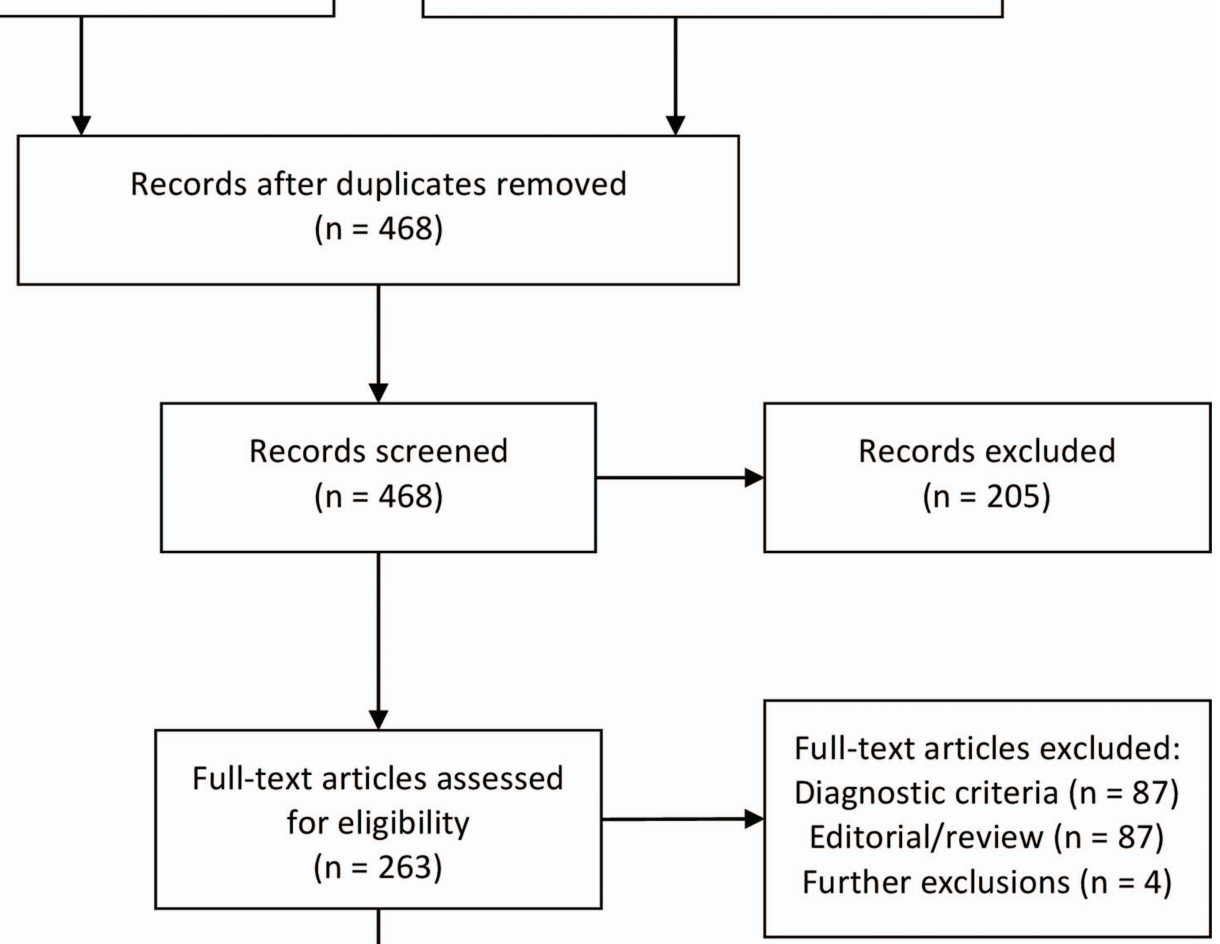

Studies included in qualitative synthesis $(n=84)$

Figure 1 Flow diagram illustrating systematic literature selection process in accordance with PRISMA guidelines. 
One study, published shortly after the search date, was identified by personal communication and was included. Two further studies were manually identified after the search date.

A total of 85 articles investigating over 40 candidate genes were eligible for inclusion in this review. These have been summarised and organised into general pathways, with genome-wide association study (GWAS) papers summarised separately, as shown in table 1. Information relating to study population, number of patient and control participants and candidate genes investigated for each study is summarised in online supplementary table S1. Additional information on candidate genes and polymorphisms, including minor allele frequency, is provided in online supplementary table S2. In all studies, genomic DNA was retrieved from blood samples unless stated otherwise. The results of studies evaluating more than one candidate gene have been described in the relevant sections, where appropriate.

\section{CANDIDATE GENE STUDIES}

\section{Lipid metabolism}

PNPLA3

The patatin-like phospholipase domain-containing protein 3 gene (PNPLA3), also known as adiponutrin, encodes a lipase enzyme expressed in adipocytes. ${ }^{9}$ The gene was first identified as a candidate for NAFLD susceptibility in a GWAS by Romeo et $a l^{10}$ which found a significant association with the rs738409 polymorphism (not included in this review as fatty liver was assessed using 1H-MRI). The rs738409 variant is thought to eliminate the lipase activity of the enzyme. ${ }^{11}$

A number of candidate gene studies have replicated the association of PNPLA3 polymorphisms in different populations (figure 2). The effects of rs738409 on histological characteristics, disease severity and NASH diagnosis have also been investigated.

Sookoian $e t a l^{12}$ performed a case-control study evaluating rs738409 polymorphism on an Argentinian population of 172 patients with NAFLD, compared with 94 controls. Discrete trait analysis showed the $\mathrm{G}$ allele to be associated with NAFLD compared with controls, and this relationship persisted with multivariate logistic regression, independently of age, sex, body mass index (BMI) and insulin status (HOMA-I). Of the patients with NAFLD, 103 were biopsied, 40 had SS and 63 had $\mathrm{NASH}$. The $\mathrm{G}$ allele variant was found to be significantly associated with disease severity $(\mathrm{GG}>\mathrm{CG}>\mathrm{CC})$ and with NASH compared with SS, with reported OR 1.88 per G allele (95\% CI 1.03 to 3.43). Increased steatosis was observed with the homozygous variant (GG) compared with the heterozygous variant, which was subsequently more severe than observed for the wild type genotype.

Hotta et $a l^{13}$ evaluated the effects of rs738409 on a Japanese cohort of 253 patients with NAFLD and 578 healthy population controls. Of the patients with NAFLD, 189 were diagnosed with NASH and 64 with SS.
The study demonstrated a significant dose-dependent relationship of SNP frequency between the NAFLD and control groups, and between patients with NASH and SS. Histologically, the variant allele had an additive effect with increased fibrosis stage, but no association was found with steatosis.

Zain $e a^{14}$ evaluated the rs738409 polymorphism in a mixed ethnicity Malaysian group of 144 patients with NAFLD and 198 healthy population controls, with subgroups of Malay, Chinese and Indian ancestry. Results indicated that NAFLD was significantly associated with the risk $\mathrm{G}$ allele with an overall OR 2.34 which remained significant after age and gender were controlled for, and the association was different between the ethnic subgroups as demonstrated in figure 2. The NAFLD group was histologically subdivided into patients with SS, NASH with fibrosis score $<2$, and NASH with fibrosis score of 2+. When NASH was compared with SS, the variant $\mathrm{G}$ allele was found to be associated with $\mathrm{NASH}$ (OR 2.64). Histological characteristics of steatosis, lobular inflammation, and hepatocellular ballooning and fibrosis grade were further analysed; the GG genotype was significantly associated with fibrosis stage but no other features. Patients with at least one $G$ allele were found to be more likely to have a fibrosis score of $\geq 2$ (OR 1.95), suggesting a relationship with disease severity.

Valenti et $a l^{15}$ investigated the association of the PNPLA3 I148M variant with histological NAFLD in a European population, comprised of 321 UK and 253 Italian patients. The variant $\mathrm{G}$ allele was found to be significantly more prevalent in the Italian patients with NAFLD compared with 179 healthy, population-matched controls, and participants with homozygous variant genotype had an increased risk of NAFLD compared with wild type. In the combined population, the variant $\mathrm{G}$ allele was found to be an independent predictor for grade 2-3 steatosis, and had a dose-dependent effect on fibrosis stage $>1$, independently of steatosis. The variant allele and GC/GG genotypes were also associated with the presence of NASH in the combined and UK cohorts, independently of BMI, steatosis and diabetes. The study also investigated allele transmission in 71 Italian family trios, observing that the variant allele was preferentially transmitted compared with the wild type.

In the same year, Valenti et $a l^{16}$ studied the rs738409 polymorphism with histological severity of NAFLD in an Italian paediatric cohort $(n=149)$. The study found that severity of steatosis was associated with the variant GG genotype (OR 18.86), independently of age, body mass and metabolic syndrome. The homozygous variant was also associated with lobular inflammation, ballooning and perivenular fibrosis, but not periportal fibrosis.

Verrijken et $a l^{17}$ investigated PNPLA3 rs378409 on a cohort of 470 overweight and obese Caucasian patients, of whom 287 underwent liver biopsy. Histological characteristics were evaluated in the biopsied subgroup, with heterozygotes and variant homozygotes found to 
Table 1 Summary and pathway overview of candidate genes included in this review

\begin{tabular}{|c|c|c|c|c|}
\hline Pathway & $\begin{array}{l}\text { Gene } \\
\text { symbol }^{9}\end{array}$ & Name $^{9}$ & $\begin{array}{l}\text { Cytogenetic } \\
\text { location }^{9}\end{array}$ & $\begin{array}{l}\text { Studies } \\
\text { (n) }\end{array}$ \\
\hline \multirow[t]{5}{*}{ Lipid metabolism } & PNPLA3 & Patatin-like phospholipase domain-containing 3 & 22q13.31 & 11 \\
\hline & LPIN1 & Lipin 1 & $2 p 25.1$ & 1 \\
\hline & PPARA & Peroxisome proliferator-activated receptor $\alpha$ & $22 q 13.31$ & 2 \\
\hline & PPARG & Peroxisome proliferator-activated receptor $\gamma$ & 3p25.2 & 5 \\
\hline & PPARGC1A & $\begin{array}{l}\text { Peroxisome proliferator-activated receptor } \gamma \text {, } \\
\text { coactivator } 1 \alpha\end{array}$ & $4 p 15.2$ & 1 \\
\hline \multirow{5}{*}{$\begin{array}{l}\text { Lipoprotein transport } \\
\text { and metabolism }\end{array}$} & APOC3 & Apolipoprotein C-III & 11q23.3 & 2 \\
\hline & $A P O E$ & Apolipoprotein E & $19 q 13.32$ & 4 \\
\hline & OLR1 (LOX-1) & Oxidised low-density lipoprotein receptor 1 & $12 \mathrm{p} 13.2$ & 1 \\
\hline & PEMT & Phosphatidylethanolamine $N$-methyltransferase & $17 p 11.2$ & 2 \\
\hline & MTTP & Microsomal triglyceride transfer protein & $4 q 23$ & 5 \\
\hline \multirow[t]{2}{*}{$\begin{array}{l}\text { Cholesterol } \\
\text { biosynthesis }\end{array}$} & SREBPF1 & $\begin{array}{l}\text { Sterol regulatory element-binding transcription } \\
\text { factor } 1\end{array}$ & $17 p 11.2$ & 1 \\
\hline & SREBPF2 & $\begin{array}{l}\text { Sterol regulatory element-binding transcription } \\
\text { factor } 2\end{array}$ & $22 q 13.2$ & 1 \\
\hline \multirow[t]{3}{*}{ Oxidative stress } & SOD2 & Superoxide dismutase 2, mitochondrial & $6 q 25.3$ & 2 \\
\hline & UCP3 & Uncoupling protein 3 & $11 q 13.4$ & 1 \\
\hline & GCLC & Glutamate-cysteine ligase, catalytic subunit & $6 p 12.1$ & 1 \\
\hline \multirow[t]{8}{*}{ Inflammatory response } & TNF & Tumour necrosis factor & $6 p 21.33$ & 7 \\
\hline & IFNL3 (IL28B) & Interferon $\lambda 3$ & $19 q 13.2$ & 1 \\
\hline & IL6 & Interleukin 6 & $7 p 15.3$ & 1 \\
\hline & IL1 & Interleukin 1 & $2 q 13$ & 1 \\
\hline & $C D 14$ & CD14 molecule & $5 q 31.3$ & 1 \\
\hline & TLR4 & Toll-like receptor 4 & $9 q 33.1$ & 1 \\
\hline & MIF & $\begin{array}{l}\text { Macrophage migration inhibitory factor } \\
\text { (glycosylation-inhibiting factor) }\end{array}$ & $22 q 11.23$ & 1 \\
\hline & ADRB3 & Adrenoceptor $\beta 3$ & $8 p 11.23$ & 1 \\
\hline \multirow[t]{2}{*}{ Metabolic hormones } & $A D I P O Q$ & Adiponectin, C1Q and collagen domain containing & $3 q 27.3$ & 3 \\
\hline & LEPR & Leptin receptor & $1 p 31.3$ & 2 \\
\hline Metabolism- & STAT3 & Signal transducer and activator of transcription 3 & $17 q 21.2$ & 1 \\
\hline \multirow[t]{4}{*}{ transcription factors } & CLOCK & Clock circadian regulator & $4 q 12$ & 1 \\
\hline & MTHFR & Methylenetetrahydrofolate reductase $(\mathrm{NAD}(\mathrm{P}) \mathrm{H})$ & $1 p 36.22$ & 2 \\
\hline & KLF6 & Kruppel-like factor 6 & $10 p 15.1$ & 1 \\
\hline & CHUK & conserved helix-loop-helix ubiquitous kinase & $10 q 24.31$ & 1 \\
\hline Hepatic iron & HFE & Haemochromatosis & $6 p 22.2$ & 6 \\
\hline accumulation & TMPRSS6 & Transmembrane protease, serine 6 & $22 q 12.3$ & 1 \\
\hline \multirow[t]{4}{*}{ Profibrogenic factors } & $A G T$ & Angiotensinogen & $1 q 42.2$ & 1 \\
\hline & AGTR1 & Angiotensin II receptor, type 1 & $3 q 24$ & 2 \\
\hline & TGFB1 & Transforming growth factor, $\beta 1$ & $19 q 13.2$ & 1 \\
\hline & $\begin{array}{l}\text { SERPINE } 1 \\
\text { (PAI-1) }\end{array}$ & $\begin{array}{l}\text { Serine peptidase inhibitor, clade } E \text { (nexin, } \\
\text { plasminogen activator inhibitor type } 1 \text { ), member } 1\end{array}$ & $7 q 22.1$ & 1 \\
\hline \multirow[t]{4}{*}{ Glucose homoeostasis } & IRS1 & Insulin receptor substrate 1 & $2 q 36.3$ & 1 \\
\hline & ENPP1 (PC-1) & $\begin{array}{l}\text { Ectonucleotide pyrophosphatase/ } \\
\text { phosphodiesterase } 1\end{array}$ & $6 q 23.2$ & 2 \\
\hline & GCKR & Glucokinase regulator & $2 p 23.3$ & 1 \\
\hline & TCF7L2 & Transcription factor 7 -like 2 & $10 q 25.2-q 25.3$ & 1 \\
\hline \multirow[t]{3}{*}{ Neurological } & CNR1 & Cannabinoid receptor 1 & $6 q 15$ & 1 \\
\hline & CNR2 & Cannabinoid receptor 2 & $1 \mathrm{p} 36.11$ & 1 \\
\hline & NCAN & Neurocan & $19 p 13.11$ & 1 \\
\hline \multirow[t]{6}{*}{ Miscellaneous } & TM6SF2 & Transmembrane 6 , superfamily member 2 & 19p13.3-p12 & 3 \\
\hline & SPINK1 & Serine peptidase inhibitor, Kazal type 1 & $5 q 32$ & 1 \\
\hline & $A B C B 11$ & $\begin{array}{l}\text { ATP-binding cassette, subfamily B (MDR/TAP), } \\
\text { member } 11\end{array}$ & $2 q 31.1$ & 1 \\
\hline & NR1H4 & Nuclear receptor subfamily 1 , group $\mathrm{H}$, member 4 & $12 q 23.1$ & 1 \\
\hline & CYP2E1 & $\begin{array}{l}\text { Cytochrome P450, family } 2 \text {, subfamily } \mathrm{E} \text {, } \\
\text { polypeptide } 1\end{array}$ & $10 q 26.3$ & 1 \\
\hline & NR112 & Nuclear receptor subfamily 1 , group I, member 2 & $3 q 12-q 13.3$ & 1 \\
\hline
\end{tabular}




\begin{tabular}{|c|c|c|c|c|}
\hline Pathway & $\begin{array}{l}\text { Gene } \\
\text { symbol }^{9}\end{array}$ & Name $^{9}$ & $\begin{array}{l}\text { Cytogenetic } \\
\text { location }^{9}\end{array}$ & $\begin{array}{l}\text { Studies } \\
\text { (n) }\end{array}$ \\
\hline & FABP2 & Fatty acid-binding protein 2 , intestinal & $4 q 26$ & 1 \\
\hline & SLC27A5 & Fatty acid transport protein 5 & $19 q 13.43$ & \\
\hline & $\mathrm{CHDH}$ & Choline dehydrogenase & $3 p 21.1$ & 1 \\
\hline & SAMM50 & Sorting and assembly machinery component & 22q13.31 & 1 \\
\hline \multirow[t]{9}{*}{ GWAS } & FDFT1 & Farnesyl diphosphate farnesyltransferase 1 & $8 p 23.1$ & 1 \\
\hline & $E F C A B 4 B$ & EF-hand calcium-binding domain 4B & $12 \mathrm{p} 13.32$ & 1 \\
\hline & LTBP3 & $\begin{array}{l}\text { Latent transforming growth factor } \beta \text { (TGF- } \beta \text { ) binding } \\
\text { protein }\end{array}$ & $11 q 13.1$ & 1 \\
\hline & $S L C 2 A 1$ & Solute carrier family 2 , member 1 & $1 \mathrm{p} 34.2$ & 1 \\
\hline & COL13A1 & Collagen, type XIII, $\alpha 1$ & $10 q 22.1$ & 1 \\
\hline & LYPLAL1 & Lysophospholipase-like 1 & $8 q 11.23$ & 1 \\
\hline & $P P P 1 R 3 B$ & Protein phosphatase 1 , regulatory subunit 3B & $8 p 23.1$ & 1 \\
\hline & PARVB & Parvin, $\beta$ & $22 q 13.31$ & 1 \\
\hline & GCKR & Glucokinase regulator & $2 p 23.3$ & 2 \\
\hline
\end{tabular}

Highlighted genes indicate associations that have been replicated in more than one histologically characterised cohort. GWAS, genome-wide association study.

have a risk of increased steatosis, lobular inflammation, severity of inflammation and ballooning, with sexadjusted and age-adjusted OR of 7.41 (CI 3.235 to 16.697), 1.86 (CI 1.046 to 3.321 ), 3.5 (CI 1.712 to 7.150 ) and 2.78 (CI 1.514 to 5.119), respectively. Fibrosis was not found to be associated.

Guichelaar et $a l^{18}$ also evaluated the association of PNPLA3 rs378409 with histological severity on obese patients. A cohort of 144 predominantly female obese patients underwent biopsy; 12 had normal histology, 60 had SS and 72 were found to have NASH. The rs378409 $\mathrm{G}$ allele was found to be associated with NASH when compared with the combined normal and patients with SS, with multivariate OR 2.5 (CI 1.1 to 5.3).

Rotman et $a l^{19}$ evaluated six polymorphisms including rs738409 in 894 adult and 223 paediatric patients within the US NASH CRN cohort. The adult cohort was compared with a population control group of 336 Caucasian men aged 50 years and over. Results showed three variants: rs738409 and rs2281135 in PNPLA3 and rs2143571

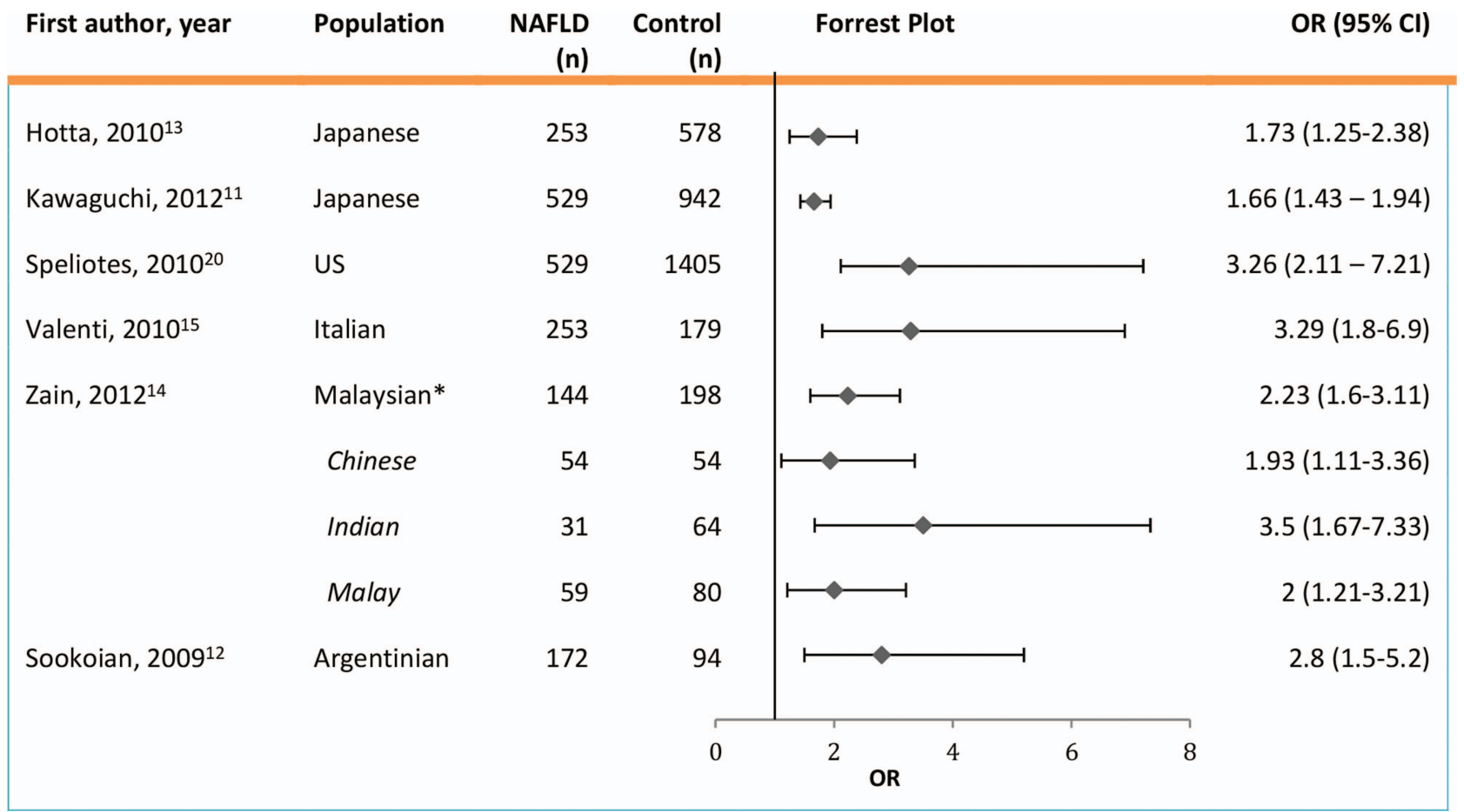

Figure 2 Studies evaluating the association between non-alcoholic fatty liver disease (NAFLD) and rs738409 of PNPLA3. ${ }^{\star}$ Combined Malaysian population including Chinese, Indian and Malay ethnic subgroups. 
in nearby $S A M M 50$ were significantly associated with NASH compared with controls. The remaining three variants investigated: rs11597390 (CPN1), rs11597086 and rs11591741 (CHUK) were not significantly associated with NAFLD. These were associated with increased fibrosis, although whether this specifically relates to fibrosis in NASH requires further investigation.

Disease severity was further investigated, with univariate analysis showing a significant association between rs738409 allele frequency and features of steatosis and both portal and lobular inflammation. Variant allele frequency was not significantly associated with histological fibrosis or cellular injury but was associated with more severe disease in a dominant pattern. This relationship persisted after factors of age, sex, BMI, diabetes and alcohol intake were controlled for. Patients with the GG and GC genotypes were more likely to have a moderate-to-severe steatosis score ( $\geq 2 ;$ OR 1.46), Mallory-Denk bodies (OR 1.55), lobular inflammation (OR 1.84) and portal inflammation (additive OR 1.57). Multivariate analysis showed a highly significant association of the $\mathrm{G}$ allele with fibrosis in an additive manner, which remained after adjustment for histological parameters of steatosis, inflammation and ballooning, suggesting an independent variable. Fibrotic bridging was associated with an adjusted OR of 1.50 for each G allele. The variant allele was also associated with an increased NAS in a dominant pattern on univariate and multivariate analyses. Polymorphisms rs2281135 and rs2143571 on chromosome 22 had similar associations with NAS. Furthermore, 438 adult patients with definite histological NASH were compared with 82 with SS and the control cohort $(n=336)$, but the rs738409 was not significantly different between SS and NASH groups. In contrast to results found by Valenti et al,${ }^{16}$ the rs738409 SNP was not associated with any histological parameters in paediatric patients.

Speliotes $e t a l^{20}$ studied 12 polymorphisms at seven loci in patients in the US NASH CRN cohort. A total of 592 patients of European ancestry were compared with a control group comprised of 1405 US and European patients enrolled in the Myocardial Infarctions Genetics Consortium (MIGen) study. The MIGen study used a control group to limit the influence of cardiovascular disease status. The rs 738409 was found to be significantly associated with both NAFLD and overall histological components (steatosis $>5 \%$, lobular inflammation, hepatocyte ballooning, NASH diagnosis and fibrosis) compared with control. However, the histological features are highly inter-related within the NASH CRN cohort, so the case-control associations may not be reflective. PNPLA3 rs2294918 and rs2281135 SNPs were also assessed, but no association was observed after controlling for the I148M variant. One limitation to this study is that the MIGen control group was not assessed for the presence of liver disease. Case-only analysis was performed within the NASH CRN cohort, and showed that rs738409 was associated with increased lobular inflammation $\geq 2$, but not hepatocyte ballooning or NASH diagnosis. When steatosis distribution was evaluated, patients with the variant allele were less likely to have perivenular centred steatosis. The authors hypothesise that this may be related to diffuse fat deposition and progression to advanced disease.

Petta et $a l^{21}$ evaluated the influence of PNPLA3 rs738409 polymorphism on NAFLD severity in a Sicilian population. Of 160 patients with NAFLD, 99 had NASH, 15 did not have NASH and 46 were described as indeterminate. The study found the PNPLA3 rs738409 variant was associated with moderate-severe steatosis (grade 2-3) by univariate analysis, but the relationship did not persist after Bonferroni correction. Multivariate logistic regression showed the homozygous variant rs738409 genotype was significantly associated with a higher score when using a recessive model.

Corbin $e t a l^{22}$ investigated 21 candidate genes on 446 patients in the Duke University Health Systems NAFLD Clinical Database and Biorepository. The study found that PNPLA3 was significantly associated with increased histological steatosis only, with an additive effect. The study did not observe any associations with $A D I P O Q$, CHDH, MTHFD1, PEMT, PPARG and STAT3 genes; further information regarding these genes is given in relevant sections.

Gorden $e t a l^{23}$ studied a cohort of 1092 US patients who underwent liver biopsy during bariatric surgery. Of the 1092 patients histologically assessed, 748 had evidence of NAFLD (187 of these diagnosed with NASH), with no evidence of steatosis in the remaining 344 patients who were used as the control group. A number of candidate genes including PNPLA3 were investigated, and rs738409 was found to be significantly associated with histological features of increased steatosis and hepatocyte ballooning. The LYPLAL, GCKR and PPP variants also studied were not associated with an increased risk of lobular inflammation, ballooning or fibrosis, but a trend towards increased steatosis was observed.

Sookoian et $a l^{24}$ performed a systematic review and meta-analysis of the PNPLA3 rs738409, comparing wild type (CC) and variant (GG) genotypes. Six of the studies with histological NAFLD assessment described above were included: Valenti, ${ }^{15}$ Valenti, ${ }^{16}$ Sookoian et $a l^{12}{ }^{12}$ Speliotes et $a l^{20}{ }^{20}$ Rotman et al, ${ }^{19}$ Hotta et al. ${ }^{13}$ Meta-analysis showed that NASH was more frequently associated with the variant genotype compared with the wild type. The variant genotype was also associated with increased inflammatory scores when four of these studies were considered, and significantly associated with fibrosis on the basis of five studies. The study also commented that the heterozygous risk was similar to the homozygous variant and suggested a dominant model for the risk of severe histological features.

\section{LPIN1}

Lipin is involved in triglyceride synthesis, lipid metabolism and adipocyte differentiation. ${ }^{9}$ The rs13412852 
variant was investigated by Valenti et $a l^{25}$ in two Italian cohorts of 142 paediatric and 115 adults with NAFLD, compared with 337 healthy controls. With regard to the paediatric patients, the variant was significantly less frequent in NAFLD compared with control. Histologically, the homozygous variant genotype was associated with reduced fibrosis (OR 0.29, CI 0.11 to 0.66 ), and trended towards reduced NASH prevalence. No significant differences were noted between the adult patients and control group, although trends towards fewer NASH and reduced fibrosis were observed with the homozygous variant. The results suggest a protective role for the minor allele; however, the paediatric results should be interpreted cautiously as were compared with an adult control group.

\section{PPAR}

The peroxisome proliferator-activated receptors are a group of nuclear receptors involved in regulating the transcription of genes involved in metabolic pathways. ${ }^{26}$ Stimulation of PPARG, along with coactivator PPARAGCA1, upregulates the expression of genes involved in adipocyte differentiation and fatty acid storage, whereas PPARA, expressed in the liver, stimulates fatty acid catabolism. ${ }^{26}$

Gawrieh $e t a l^{27}$ investigated the PPARG Pro12Ala and C1431T variants in a US population. DNA was extracted from liver biopsy samples of 212 patients with NAFLD, and blood samples from 62 controls. Results did not reach statistical significance for allele frequency or histological characteristics. Genetic modelling and haplotype analysis of the two PPARG variants showed that patients with both minor alleles (GT) had a lower risk of NAFLD, but also increased inflammation and advanced fibrotic change, when compared with patients with both major alleles (CC). However, these results should be interpreted with caution, as there was a low successful genotyping rate of $65 \%$ from the biopsy samples.

Rey et $a l^{28}$ studied the effect of the PPARG Pro12Ala polymorphism in German patients with fatty liver disease, including 100 patients with alcoholic liver disease and 263 patients with NAFLD. Genomic DNA from fatty liver patients was extracted from biopsy samples and compared with 259 blood samples of healthy controls. A slightly increased but non-significant relationship was seen in variant allele incidence between NAFLD and control groups, and there was no association with histological inflammation in NAFLD.

Dongiovanni et al, 2010 28 investigated the PPARG (Pro12Ala) and PPARA (Leu162Val) variants in a biopsyproven NAFLD cohort of 202 Italian patients, compared with 346 healthy controls. Analysis showed that the allele frequency was not significantly different between NAFLD and control, and no significant difference was observed in histological characteristics.

The same variants of the PPARA and PPARG genes (Leu162Val and Pro12Ala, respectively) were also investigated by Domenici et al. ${ }^{29}$ A cohort of 103 Brazilian patients with NAFLD was compared with 103 healthy controls; of the NAFLD group, 89 had histological NASH and 14 had SS. There was no significant difference in allelic frequencies between NAFLD and control, but the Ala PPARG variant was less common in the NASH group compared with the control group. Histologically, the wild type PPARA genotype (LeuLeu) was found to be associated with more severe fibrosis.

Yoneda $e t a l^{30}$ performed a case-control study investigating 15 SNPs in the PPARGC1A candidate gene, in a Japanese cohort of 115 patients with NAFLD and 441 healthy population controls. Results showed that the $\mathrm{T}$ allele of rs2290602 was significantly associated with NAFLD (OR 2.73) in the dominant mode when compared with control. Within the NAFLD group, 65 patients had histological NASH, and 50 had SS; a trend towards increased T allele frequency in the NASH group was noted, however this did not reach statistical significance, possibly a result of the small sample size.

Sahebkar ${ }^{31}$ performed a meta-analysis of the PPARG Pro12Ala polymorphism. Seven studies were included in the quantitative review, including the four histologically proven studies described above. Results of the meta-analysis showed no protective or predisposing effect of the variant in any genetic model. When the results of Gawrieh et $a l^{27}$ were excluded as an outlier due to high BMI, the variant was significantly associated with NAFLD, and the author proposes the effects of obesity may complicate the relationship.

\section{Lipoprotein transport and processing APOC3, APOE and ORL1}

The apolipoprotein C-III, encoded by $A P O C 3$ gene on chromosome 11, is a very low-density lipoprotein (VLDL) component that functions to inhibit lipoprotein lipase and hepatic lipase. ${ }^{9}$ Mutations in $A P O C 3$ are known to be associated with hypertriglyceridaemia and it is hypothesised that this protein delays catabolism of triglyceride-rich particles and is involved in hepatic lipid processing. ${ }^{9}$ The $A P O E$ gene on chromosome 19 encodes apolipoprotein $\mathrm{E}$, the main apoprotein of the chylomicron that is involved in endocytosis and clearance of chylomicron and VLDL particles by the liver. ${ }^{9}$ Mutations in this protein are known to be associated with familial dysbetalipoproteinaemia. ${ }^{9}$ Oxidised low-density lipoprotein (LDL) receptor 1 is encoded by ORL1 on chromosome $12 .{ }^{9}$ The receptor binds oxidised LDL, which is then internalised and degraded in the liver. ${ }^{9}$

Valenti et $a l^{2}$ investigated APOC3 polymorphisms T-455C and C-482T in a cohort of 758 European (Italian and UK) patients with NAFLD. The case-control study between the Italian patients with NAFLD and 316 healthy Italian controls found no protective effect of the APOC3 wild type, and no significant association with histological characteristics or NASH diagnosis was observed. Verrijken et $a l^{17}$ also investigated the rs2854117 variant of APOC3, finding no significant associations with disease severity, fibrosis or other histological characteristics. 
Sazci et $a l^{33}$ evaluated apolipoprotein E polymorphisms in 57 Turkish patients with NASH, compared with 245 healthy controls. The study found that the APOEE 3 isoform was associated with an increased risk of NASH, whereas the heterozygous $A P O E \varepsilon 3 \varepsilon 4$ was protective.

De Feo $e t a b^{34}$ investigated the three major isoforms of $A P O E$ on an Italian population of 310 patients with NAFLD (109 biopsy proven) and 422 population controls. The case-control study found that at least one $A P O E \varepsilon 4$ allele significantly reduced the risk of NAFLD (OR 0.51 , CI 0.28 to 0.93 ) when compared with the homozygous wild type. Histological assessment in the biopsied subgroup found no significant association with APOE genotype and fibrosis.

Gambino $e t a l^{55}$ compared 29 Italian patients with NASH with 27 controls but found no significant difference in APOE polymorphisms; however, this study has less power due to small sample size. Musso $e t a l^{P^{6}}$ also investigated $A P O E$ isoforms on a larger Italian population, comparing 78 patients with NAFLD, 34 of whom were biopsied and diagnosed with NASH, to 156 healthy controls. APOE genotypes were not found to be significantly different. The study also compared 40 Italian patients with NASH with 40 ORL1 genotype-matched controls and concluded that the ORL1 IVS4-14 G allele was associated with the severity of steatosis, necroinflammation and fibrosis.

\section{PEMT}

Phosphatidylethanolamine $N$-methyltransferase (PEMT) is an enzyme in the liver that catalyses the conversion of phosphatidylethanolamine to phosphatidylcholine, ${ }^{9}$ a substance that is required for VLDL secretion. Dong et $a l^{37}$ evaluated the prevalence of the PEMT V175M allele in a Japanese population between 107 patients with $\mathrm{NASH}$, a normal control population $(\mathrm{n}=150)$ and a cohort of 100 patients with chronic hepatitis C. Both the $\mathrm{M}$ allele frequency and $\mathrm{M} /-$ genotype were significantly increased in the NASH participants when compared with the control and patients with chronic hepatitis C. There were no significant differences in genotype or allele frequency between the normal and hepatitis C controls, indicating that the association observed is likely to be more specifically related to NASH than viral hepatitis.

\section{MTTP}

Microsomal triglyceride transfer protein (MTTP) is a heterodimeric protein involved in triglyceride, phospholipid and cholesterol ester transport, ${ }^{9}$ and lipoprotein assembly. The MTP gene located at $4 \mathrm{q} 23$ encodes the $88 \mathrm{kD}$ large subunit of MTTP, and mutations in this protein are associated with familial abetalipoproteinaemia. ${ }^{9}$ The encoded variant of $M T P-493$, with $\mathrm{C}$ to $\mathrm{G}$ transversion, undergoes less transcription than the wild type protein. ${ }^{38}$

Namikawa $e t a l^{38}$ studied the variant $-493 \mathrm{G}$ allele of MTP in 63 biopsy proven patients with NASH with 150 healthy controls in a Japanese population. The MTP allele and homozygous variant genotype were both found to be significantly associated with NASH compared with controls. The variant genotype was also associated with increased steatosis and increased histological grade of NASH when compared with the heterozygous carriers.

Gambino et $a \vec{l}^{35}$ described above also investigated the frequency of the homozygous MTP variant between patients with NASH and controls. No significant difference in allele frequency was observed between Italian patients with NASH and controls, but within the NASH group, the severity of histological steatosis, inflammation and fibrosis was increased in patients with the variant genotype when compared with heterozygotes and homozygous wild type patients. However, these results should be interpreted with caution due to the limited sample size of 27 patients.

Carulli $e$ t $a l^{39}$ performed a candidate gene study in an Italian population investigating the three candidate genes MTP, PCIKI and IL6. The study compared 114 patients with NAFLD, including 59 who underwent biopsy, against 79 healthy population controls. With regard to $M T P$, the case-control study was not significant, and there was no association with histological characteristics or NASH diagnosis within the biopsied group. The study also found no association with the PCIK I121Q variant, and results pertaining to IL6 are described in the relevant section.

Oliveira et $a l^{40}$ evaluated the MTP -493 (C/G) polymorphism in a cohort of 139 Brazilian patients with NAFLD, comprised of 45 with SS and 86 with NASH. The MTP G allele was not found to be associated with NAFLD when compared to 141 controls or with NASH when compared to SS.

El-Koofy $e t a t^{41}$ investigated the association of MTTP and SOD2 SNPs with NAFLD in a paediatric Egyptian cohort. A total of 76 children with NAFLD were compared with 20 age-matched and sex-matched healthy controls. Within the NAFLD group, 33 underwent liver biopsy, and of these, 8 had SS, NASH was present in 7 cases, and the remaining 18 samples showed normal histology. The homozygous -493 MTP genotype (TT) was not present in any of the 15 patients with NASH or SS. No association was reported with the SOD2 118T/C variant, but when the homozygous wild types of MTP (GG) and SOD (TT) were combined, the study reported a significant risk of NASH compared with controls (OR 54, CI 4.1 to 707). These results should also be treated with caution as only seven patients diagnosed with NASH were studied.

\section{Cholesterol biosynthesis}

SREBP

Sterol regulatory element-binding proteins are leucine zipper transcription factors that regulate the transcription of enzymes involved in cholesterol biosynthesis. Musso et $a t^{42}$ investigated the effect of the rs11868035 variant of SREBP factor $1 \mathrm{C}$ on histological severity in 42 
biopsy-proven Italian patients with NAFLD. The wild type and heterozygous genotypes were found to be associated with an increased severity of steatosis, necroinflammation, increased NAS, increased fibrosis score and increased prevalence of NASH when compared with the mutant genotype. Multivariate analysis showed this $S R E B P 1 C$ polymorphism to be independently associated with both severe steatosis and NASH. In a separate study, the same group evaluated the effect of polymorphisms in SREBP factor 2 in biopsied patients with NAFLD. ${ }^{43}$ The study reported that patients with heterozygous and homozygous variant genotypes demonstrated an increased severity of histological characteristics and NASH diagnosis compared with wild type patients. The $S R E B P F 2$ variant allele was found to be an independent predictor of NASH within these patients (OR 2.92, CI 2.08 to 4.18$)$.

\section{Oxidative stress}

There are a number of theories regarding the role of cellular oxidative stress as a factor contributing to the development of NAFLD and NASH. It is therefore unsurprising that a number of studies have investigated genetic variants that might reduce the ability of hepatocytes to protect against oxidative stress, including polymorphisms in the SOD2, UCP3 and GCLC genes.

\section{SOD2}

The superoxide dismutase 2 (SOD2) gene on chromosome 6 encodes the enzyme manganese superoxide dismutase. ${ }^{9}$ This is located on the outer mitochondrial membrane, and catalyses the conversion of superoxide by-products of oxidative phosphorylation to hydrogen peroxide and oxygen. ${ }^{9}$ Mutations in SOD2 have been previously associated with idiopathic cardiomyopathy, certain cancers and motor neuron disease. ${ }^{9}$ The rs4880 C47T polymorphism of SOD2 is a $\mathrm{C}$ to $\mathrm{T}$ transversion that results in a valine to alanine substitution in the mitochondrial-targeting region of the protein and may alter the tertiary protein structure. ${ }^{44}$

Al-Serri $e t a t^{4}$ conducted a linkage study on 71 Italian families and found that the C47T SNP was preferentially transmitted. The study then evaluated the C47T SOD2 polymorphism in a European cohort of 510 patients with NAFLD. The study showed the SOD2T variant was associated with advanced fibrosis (scores of $>1$ ) with an additive effect. When the PNPLA3 rs738409 was controlled for, the SOD2 was still associated with the degree of histological steatosis, and was an independent risk factor for advanced fibrosis. However, the SOD2 allele did not affect the diagnosis of NASH.

Namikawa $e t a l^{8}$ performed a case-control study between 63 patients with NASH and 150 healthy controls in a Japanese population to evaluate the SOD2 C47T allele. The study found the homozygous variant genotype (TT) was significantly associated with NASH, however the $\mathrm{T}$ allele frequency was not. The MTP polymorphism was also investigated (described above), and the proportion of patients with NASH with both GG $(M T P)$ and TT (SOD2) genotypes was significantly increased compared with controls.

\section{UCP3}

Uncoupling protein 3 encoded by the UCP3 gene is a mitochondrial proton carrier located at $11 \mathrm{q} 13,{ }^{9}$ primarily expressed in skeletal muscle. ${ }^{9}$ The protein is a mitochondrial anion carrier and facilitates the transport of anions from the inner to outer mitochondrial membrane, thus reducing the mitochondrial membrane potential. ${ }^{9}$ The protein is considered to be protective against oxidative stress from $\beta$ oxidation of fatty acids. ${ }^{9}$ Aller $e t a l^{45}$ investigated the $-55 \mathrm{C} / \mathrm{T}$ polymorphism of UCP 3 in a cohort of 39 obese patients who underwent liver biopsy. The heterozygous genotype was found to be associated with an increase in both moderate-to-severe histological inflammation and moderate-to-severe steatosis.

\section{GCLC}

The catalytic subunit of glutamate-cysteine ligase (GCLC) is involved in the synthesis of glutathione (GSH) ${ }^{9}{ }^{\mathrm{GSH}}$ is a tripeptide that counteracts cellular oxidative stress from reactive metabolites through thiol group reduction. ${ }^{46}$ Oliveira $e t a l^{40}$ evaluated the $-129 \mathrm{C} / \mathrm{T}$ GCLC polymorphism in a cohort of 139 Brazilian patients with NAFLD, 45 with SS and 86 with NASH. The investigators observed a significant association between the Tallele of GCLC with patients with NASH when compared with the SS group.

\section{Inflammatory response}

A key histological component that differentiates SS from more severe disease is the inflammatory response. Polymorphisms of genes encoding components of the immune response, including proinflammatory cytokines such as tumour necrosis factor (TNF), the interleukin (IL) family of molecules and macrophage migration inhibitory factor (MIF), have been investigated for potential associations with NAFLD and disease progression. Toll-like receptor 4 (TLR4), a pathogen recognition molecule, and the CD14 molecule expressed by macrophages are lipopolysaccharide (LPS) cell surface antigens involved in the immune response. ${ }^{9}$

\section{TNF}

Valenti et $a l^{47}$ investigated two TNF polymorphisms (TNFA 238 and TNF2 308) in 99 patients with NAFLD (53 biopsied) and compared with 172 healthy controls. The allele frequency and genotype of TNF2 was not different between NAFLD and controls; however, both the TNFA variant allele and genotype were significantly increased in NAFLD. In the biopsied subgroup, 35 patients had NASH whereas 18 had SS. A trend towards a higher prevalence of $T N F$ polymorphisms in NASH subgroup was observed when compared with those with SS, but this did not reach statistical significance, which may be due to the small sample size. Yang $e t a l^{48}$ investigated these two TNF variants in obese children; 
histologically, 61 were normal and used as control, 17 had SS and 33 had NASH. No significant difference was observed.

$\mathrm{Hu}$ et $a t^{49}$ also investigated the same variants, comparing a cohort of 189 Chinese patients with NAFLD, 44 diagnosed histologically, to 138 healthy controls. Neither variant was homozygous in either the patient or control groups. The heterozygous genotype and A allele frequency of the TNFA variant was found to be significantly associated with NAFLD compared with control, with relative risk 2.19. No histological associations were observed in the biopsied subgroup, although the sample size for comparison was small.

Chowdhury et a $\tilde{l}^{\tilde{0}}$ evaluated the effect of the -308 and $-238 \mathrm{TNF}$ variants on fibrosis in NAFLD, investigating 29 Indian patients with biopsy-proven NAFLD. The variants were not found to be associated with fibrosis severity; however, DNA amplification only worked in 25 cases, reducing the sample size.

Aller et $a{ }^{\tilde{1}}$ investigated the $-308 \mathrm{TNF}$ polymorphism on histological characteristics in 66 patients with NAFLD and 213 obese controls. Variant frequency was not significantly different between patients and controls, although within the patient group those carrying the heterozygous variant $(\mathrm{n}=15)$ had significantly more severe inflammation and fibrosis than those with wild type genotype; however, the sample size is small.

Tokushige et $a \tilde{l}^{2}$ investigated six TNF polymorphisms in a Japanese population of 102 patients with NAFLD and 100 controls, and found no significant differences between the NAFLD and control groups. Of the patients with NAFLD, 36 had SS and 66 had NASH: the -1031C and $-863 \mathrm{~A}$ variants were significantly more frequent in the NASH group compared with SS, but there were no associations with histological features.

Wong $e$ t $a \bar{l}^{33}$ investigated the role of three variants of TNF in a Chinese population. A cohort of 79 patients with NAFLD, comprising 61 individuals with SS and 18 patients diagnosed with NASH, was compared with 40 healthy population controls. The results showed no significant differences in the frequency of the three $T N F$ polymorphisms investigated.

\section{Interleukins}

The study by Carulli et $a i^{99}$ described above also evaluated the IL-6-174 G/C SNP, comparing 114 patients with NAFLD against 79 controls. Of the NAFLD group, 59 patients underwent liver biopsy; 29 had NASH, 30 had NAFLD. The case-control study showed that $I L-6$ GC and CC genotypes were significantly more prevalent in the NAFLD group, and furthermore, multivariate logistic regression showed the association of GC and CC genotype with NAFLD was independent of age, gender and BMI (OR 4.116, CI 1.126 to 15.048). Histological features were compared between biopsied patients with NASH and NAFLD. The IL-6 CG and CG variants were associated with NASH (OR 7.035, CI 1.167 to 42.394), but not histological characteristics.
Petta et $a l^{21}$ investigated the rs12979860 and rs8099917 variants of IFNL3, also known as IL28B, on histological features in 160 Sicilian patients with NAFLD. The study found the wild type (CC) genotype of rs12979860 was independently linked to moderate-severe lobular inflammation, remaining significant after Bonferroni correction. The rs12979860 wild type was also associated with severe fibrosis by univariate analysis, but not after Bonferroni correction, and multivariate logistic regression was not significant. The rs8099917 was not reported to show any significance.

Nozaki et $a \tilde{D}^{4}$ investigated the association between $-511 \mathrm{~T} / \mathrm{C}$ variant of $I L 1 B$ and B3 adrenergic receptor $190 \mathrm{~T} / \mathrm{A}$ polymorphism on a cohort of 63 Japanese patients with NASH. Case-control study showed that the $I L-1 T$ allele and TT genotype were significantly more frequent in the NASH group compared with 100 healthy controls. The B3ADRC mutant allele was also found to have a higher prevalence in the NASH group.

\section{MIF}

Akyildiz et $a \bar{l}^{5}$ investigated the association of the -173 G/C MIF variant with NAFLD and severity. Ninety-one patients with NAFLD stratified as 37 with NASH, 44 probable NASH and 10 SS were compared with 104 healthy controls. MIF variant genotype and allele were not significantly different between NAFLD cases and control, or within the NAFLD groups.

\section{LPS receptors}

In a brief communication, Brun et a $\tilde{p}^{6}$ describe the effect of polymorphisms in genes encoding the TLR4 and CD14 LPS receptors on 28 patients with NAFLD, including 21 with NASH, who were compared with 52 healthy controls. No significant association was seen with TLR4; however, the CD14 homozygous mutant genotype was not present in the seven patients with NAFLD without NASH, and was significantly increased in patients with NASH than controls.

\section{Metabolism}

\section{Hormones}

Adiponectin, encoded by $A D I P O Q$, and leptin are hormones secreted by adipocytes. Adiponectin is involved in the regulation of energy homoeostasis and metabolism, particularly through enhancement of insulin sensitivity. ${ }^{9}$ Reduced plasma levels of adiponectin have been associated with features of the metabolic syndrome including NAFLD. Leptin acts through its receptor, encoded by $L E P R$, to stimulate satiety and reduce food intake, and also increase energy expenditure. ${ }^{9}$ Studies have investigated polymorphisms in $A D I P O Q$ and $L E P R$ for association with NAFLD.

\section{$A D I P O Q$}

Wong $e t a \tilde{l}^{3}$ studied four SNPs in the adiponectin gene, comparing a cohort of 79 Chinese patients with NAFLD with 40 population controls. Within the NAFLD group, 61 patients had SS and 18 were diagnosed with NASH. 
The results showed no significant difference in any of the four $A D I P O Q$ polymorphisms studied between the NAFLD and control groups, or histological severity within the NAFLD group.

Tokushige et $a l^{57}$ investigated adiponectin polymorphisms +45 and +276 in a Japanese population. A cohort of 119 patients with NAFLD was compared with 115 healthy population controls. There were no significant differences in the frequency of either SNP between the NAFLD and control groups, or between the patients with NASH and SS. However, the $+45 \mathrm{G}$ allele frequency and homozygous variant genotype (GG) were significantly associated with histologically severe fibrosis. Further statistical analysis demonstrated that $+45 \mathrm{GG}$ was an independent factor of severe fibrosis.

Gupta et $a \bar{p}^{8}$ studied two functional polymorphisms of the adiponectin $(A D I P O Q)$ gene: $+45 \mathrm{~T} / \mathrm{G}$ and $-11377 \mathrm{G} / \mathrm{C}$ on an Indian population. A cohort of 137 patients with NAFLD, including 113 who underwent liver biopsy, was compared with 250 controls. The case-control study showed both homozygous variants to be significantly more prevalent in the NAFLD cohort, with OR 6.7 (CI 1.5 to 28.6) and OR 5.1 (CI 0.6 to 14) for the -11377 (CC) and $+45(\mathrm{GG})$ genotypes, respectively. When the biopsied subgroup was considered, patients carrying the -11377 variant allele correlated with necroinflammatory grade were compared with wild type patients.

\section{LEPR}

Zain $e$ t $a \tilde{l}^{9}$ investigated the rs1137100 and rs1137101 polymorphisms of the leptin receptor on a multiethnic Malaysian cohort. Results indicated that both polymorphisms were significantly associated with NAFLD, but were not specific to any of the ethnic groups studied. Of the NAFLD cohort, 33 patients had SS and 111 had NASH. Histologically, the rs1137100 GG genotype was observed to be associated with a decreased fibrosis score, and the G allele was protective against fibrosis. The interaction between the PNPLA3 and leptin receptor polymorphisms was also investigated using a two-locus model, and a significant effect was noted. Aller $2012^{60}$ investigated the lys656Asn variant of LEPR on 76 obese participants with biopsy-proven NAFLD. There were no significant differences in histological features between genotypes.

Swellam and Hamdy ${ }^{61}$ investigated the leptin receptor SNP rs6700896 in an obese Egyptian cohort of 90 patients with NAFLD and compared with 30 lean, healthy controls. Of the patients with NAFLD, 30 were described as having mild steatosis and 60 had moderate-to-severe steatosis. The mutant allele was not present in the control group, and the mutant genotype was found to be associated with moderate-to-severe steatosis in patients with NAFLD, when compared with those with mild steatosis.

\section{Transcription factors}

STAT3

The STAT3 gene, encoding signal transducer and activator of transcription 3 (STAT3), is a transcription factor that when activated by growth factors and cytokines, mediates expression of genes involved in a number of different pathways, including cell growth, metabolism, apoptosis and possibly energy homoeostasis $(8,53)$.

Sookoian et al ${ }^{62}$ investigated three polymorphisms in the STAT3 gene in an Argentinian population: rs2293152, rs6503695 and rs9891119. A cohort of 108 patients with NAFLD, of whom 68 underwent liver biopsy, was compared with 55 healthy controls. In the case-control study, univariate analysis after multiple comparison corrected by permutation tests found significant associations of allelic frequencies of both the rs6503695 and rs9891119 variants with NAFLD. The NAFLD group was histologically divided into fatty liver (not biopsied), fatty liver (biopsied) and definite NASH groups and Spearman rank testing was performed. A significant association was observed with the rs9891119 A allele with increased histological severity, which persisted after BMI was controlled for $(\mathrm{AA}>\mathrm{AC}>\mathrm{CC})$. However, this result should be interpreted with caution because, although the non-biopsied patients had normal liver function tests (LFTs), histological analysis was not performed on this group. No significant association was observed between STAT3 variants and inflammation or fibrosis.

\section{CLOCK}

The $C L O C K$ gene encodes a transcription factor involved in regulation of circadian rhythm and metabolism, and variants in $C L O C K$ are thought to influence both behaviour and obesity. ${ }^{9}$ Sookoian $e t a l^{63}$ studied six variants of the $C L O C K$ candidate gene in an Argentinian population. A cohort of 136 patients with NAFLD was compared with 64 controls; 91 patients were biopsied and 56 were diagnosed with NASH. Univariate analysis showed that both rs11932595 and rs6843722 SNPs were significantly associated with NAFLD compared with control. CLOCK variant combinations were analysed using multimarker analysis, some of which showed association, but these did not retain significance with correction for multiple testing. Further omnibus analysis including the six SNPs did show significant results between NAFLD and control, but no individual markers contributed significantly to this. When histology was considered, the rs1554483, rs6843722 and rs6850524 were all significantly associated with disease severity, as were (rs11932595/rs6850524 GC) and (rs4580704/rs6843722 CA) haplotypes, although this should be interpreted with caution because again the entire NAFLD cohort did not undergo biopsy. Within the NASH subgroup, a significant association with overall fibrosis score was observed with rs1554483, rs6843722 and rs4864548.

\section{MTHFR}

The enzyme methylenetetrahydrofolate reductase (MTHFR) catalyses 5'10-methylenetetrahydrofolate reduction, producing $5^{\prime}$ methyltetrahydrofolate, which is further involved in the formation of methionine from homocysteine. ${ }^{64}$ Methionine is an important methyl 
donor utilised during the epigenetic process of DNA methylation, and mutations in MTHFR have been associated with a number of disease processes. ${ }^{64}$

Serin $e t a{ }^{65}$ evaluated the MTHFR C677T polymorphism in 53 Turkish patients with NAFLD, with 23 patients with $\mathrm{NASH}$, defined by a $\mathrm{NAS}^{3}$ of $\geq 5$. The distribution of the polymorphism was found not to be significant between controls $(\mathrm{n}=282)$ and NAFLD, or between NAFLD and NASH. Sazci et $a l^{64}$ also investigated the relationship between polymorphisms of MTHFR and NASH in a Turkish population. The two SNPs investigated-C677T and A1928C—were compared between 57 patients with histological NASH, with 324 healthy population controls. Results indicated A1298C was significantly associated with NASH, with the wild type AA being protective against NASH, but there was no significant association between NASH and 677T. The study also looked at compound genotypes and observed that the CC/AC in men and CC/CC genotypes in women were associated with NASH.

Assy $e t a l^{66}$ evaluated thrombotic risk factors, including prothrombin, factor V Leiden and MTHFR mutations. Comparisons were made between 15 patients with fatty liver, 15 with NASH and 15 with chronic viral hepatitis. No significant differences were observed; however, only one variant allele was found within the groups studied.

\section{KLF6}

The Kruppel-like factor 6 encoded by KLFG on chromosome 10 is a zinc finger transcription factor which functions as a tumour suppressor, and polymorphisms have been implicated in various cancer types. ${ }^{9}$ Miele $e t a b^{67}$ investigated the Kruppel-like factor 6 rs37508611 IVSI-27 G>A polymorphism on two cohorts of 306 UK and 109 Italian patients with biopsy-proven NAFLD. In the combined and UK cohorts, a significant reduction in fibrosis score was seen in heterozygous patients compared with homozygous wild type, but results did not reach statistical significance in the Italian cohort, possibly due to the reduced sample size. Logistic regression analysis showed the wild type genotype was a significant independent risk fact for the presence of fibrosis, with (OR 2.76, CI 1.295 to 5.908). This study also investigated inheritance patterns in 71 Italian family trios, which indicated a preferential transmission of the wild type allele.

\section{Hepatic iron accumulation \\ HFE}

The HFE gene on chromosome 6 encodes a membrane protein that is hypothesised to regulate iron absorption through the interaction of transferrin with its receptor; homozygotes for mutations (C282Y or H63D) in this gene develop hereditary haemochromatosis. ${ }^{9}$

Valenti et $a l^{68}$ evaluated polymorphisms in $H F E$ in an Italian population comprising 134 patients with NAFLD and 291 healthy controls. Within the NAFLD cohort, 67 underwent biopsy, and NASH was found in 42 patients, whereas 25 had SS. The case-control analysis showed that C282Y (but not H63D) was significantly more prevalent in patients with NAFLD compared with controls. There were no significant differences in frequency of either polymorphism between patients with and without $\mathrm{NASH}$, although only a percentage of the patients with NAFLD were histologically assessed. The same group ${ }^{69}$ studied the HFE C282Y and H63D mutations in a larger Italian population. The study compared a cohort of 587 histologically diagnosed patients with NAFLD to 184 healthy controls. The study found the frequency of variant alleles was not significant. It was noted that hepatocellular iron deposition was an independent risk factor for moderate-to-severe fibrosis, but no significant association was found between HFE genotype and severity of fibrosis.

Deguti et $a l^{70}$ evaluated 32 Brazilian patients with histological NASH and found no evidence of association between either C282Y or H63D variant, HFE mutations with histological injury and did not observe significant iron deposition. Zamin et $a l^{71}$ also studied the effects of these $H F E$ variants on histological features. A cohort of 29 Brazilian patients with NASH was compared with 20 healthy controls and 20 patients with hepatitis C. The study found the prevalence of the mutation was similar between groups, with no significant association between mutation and fibrosis score or other histological characteristics. An association between liver iron overload and mutation was noted, but this did not correlate with fibrosis score.

Raszeja-Wyszomirska et $a l^{72}$ studied the effects of C282Y and H63D HFE mutations on a Polish cohort of 62 biopsy-proven patients with NAFLD. The authors scored patients on fibrosis as described and compared those with no or mild fibrosis (score $0-2, n=48$ ) against those with advanced fibrosis (score 3-4, $\mathrm{n}=14$ ). It was observed that in cases with severe fibrosis, the variant H63D allele was associated with increased serum levels of total cholesterol and LDL cholesterol, but no other associations between histological disease severities were apparent.

Nelson $e t a l^{73}$ characterised the C282Y and H63D HFE SNPs in 786 participants in the NASH CRN cohort. The relationship between genotype and histological features, including steatosis, inflammation, hepatocyte ballooning, fibrosis stage and NAS, ${ }^{3}$ was evaluated. It was found that participants with the C282Y mutant allele were more likely to have increased iron deposition and hepatocellular pattern, but H63D was not associated with increased hepatic iron accumulation. Both HFE SNPs were shown to be associated with an increased steatosis grade when compared with wild type, and H63D allele was also associated with an increase in NAS. A significant reduction in hepatocyte ballooning and definitive NASH associated with the C282Y SNP was also observed; however, there was no association between HFE SNPs and fibrosis stage. The authors concluded that the H63D allele was an independent risk factor for the 
highest grade steatosis, lobular inflammation and NAS $\geq 5$, and definitive diagnosis of NASH.

\section{TMPRSS6}

The TMPRSS6 gene encodes transmembrane protease, serine 6 , a cell surface enzyme involved in liver matrix remodelling. ${ }^{9}$ The encode enzyme also cleaves a co-receptor necessary for the transcription of hepcidin; therefore, mutations in this gene can affect cellular iron status. $^{74}$

Valenti et $a l^{74}$ compared the frequency of the TMPRSS6 AV736 polymorphism in a cohort of 216 Italian patients against a 271 population control. The $\mathrm{V} / \mathrm{V}$ genotype was observed to be associated with reduced hepatic iron and less severe hepatocyte ballooning, but other histological characteristics of NASH were similar. The study concluded that TMPRSS6 is not a risk factor for the development of NAFLD.

\section{Profibrogenic factors}

Angiotensin II acts through two receptors to mediate a number of biological effects including vasoconstriction. The angiotensin II receptor 1, encode by AGTR1 on chromosome 3 , is a receptor expressed in the liver by stellate cells that initiates a response to tissue injury. ${ }^{9} 75$ Receptor activation is thought to promote profibrogenic cytokines including transforming growth factor $\beta 1$ (TGFB1) which may also have a role in lipid accumulation, ${ }^{76}$ and SERPINE1 inhibits enzymes involved in fibrinolysis. ${ }^{9}$ Variants in these genes have been investigated as potential risk factors for NAFLD susceptibility.

Yoneda et $a l^{77}$ performed a case-control study of 167 patients with NAFLD (61 with SS and 106 with NASH) and 435 healthy controls to investigate 12 SNPs of AGTR1. It was found that five SNPs were significantly associated with NAFLD when compared with the control group, with rs3772622 having the strongest association. When the SS and NASH groups were compared, the rs3772622 polymorphism was also found to be associated with an increased fibrosis index, with an additive effect.

Zain $e t a l^{75}$ investigated polymorphisms of AGTR1 in a mixed ethnicity Malaysian cohort of 144 patients with NAFLD compared with 198 healthy population controls. A protective effect against NAFLD was observed in the Indian ethnic subgroup compared with controls, but no other significant differences were noted. There were also no significant associations when patients with NASH were compared with those with SS; however, the GG genotype of rs772622 was shown to be associated with increased severity of histological fibrosis. The interaction between the PNPLA3 rs738409 variant and AGTR1 was also analysed; an association with NAFLD susceptibility was observed between the PNPLA3 variant with both the rs772627 and rs3772630 polymorphisms.

Dixon et $a l^{76}$ analysed liver biopsy samples from 105 obese Australian patients and evaluated TGFB1 and AT polymorphisms, using reported population data as controls. Of the patients, 103 were diagnosed as having steatosis, and 36 of these also had NASH. The study found no significant association between the polymorphisms investigated separately and presence of fibrosis; however, a combination of the two homozygous mutant genotypes was found to be an independent predictor of advanced fibrosis.

\section{SERPINE 1}

Espino et $a l^{78}$ compared the $4 \mathrm{G} / 5 \mathrm{G}$ variant of SERPINE1 (PAI-1) in 50 obese Chilean patients undergoing bariatric surgery and 71 controls. Within the obese patient group, 21 were histologically normal, 9 had steatosis and 20 met criteria for NASH. No differences in variant frequency were observed between patients and controls, or those with and without NASH-related fibrosis.

\section{Glucose homoeostasis \\ INSR}

The insulin receptor is a tyrosine kinase membrane receptor involved in glucose homoeostasis. The protein encoded by ENPP1 on chromosome 6 is a cell membrane protein that may be involved in insulin sensitivity and IRS- 1 encodes a substrate involved in the insulin receptor pathway. ${ }^{9}$

Dongiovanni et $a l^{79}$ evaluated the effect of polymorphisms ENPP1 rs1044498 and IRS-1 rs1801278 in a European cohort. A case-control study of 240 Italian patients with NAFLD and healthy population controls showed no significance. Histological features were assessed on a cohort of 702 Italian patients; both polymorphisms were associated with increased fibrosis and the rs1044498 variant allele of ENPP1 was associated with fibrosis severity.

\section{GCKR}

GCKR encodes glucokinase regulator, a protein that modulates the activity of the enzyme glucokinase in liver cells by reversibly binding to form an inactive complex. ${ }^{9}$ Tan $e t a l^{80}$ investigated the GCKR rs780094 (C>T) and rs1260326 (C>T) SNPs on a mixed ethnicity Malaysian cohort of 144 patients with NAFLD and 198 controls. The variant $\mathrm{T}$ allele frequencies of each SNP was found to be more prevalent in patients with both NAFLD and NASH when compared with controls; however, when the ethnic subgroups were considered, the relationship was only significant in the Indian population, not those of Chinese or Malay ethnicity. Owing to the mixed ethnicity of this cohort, the results should be interpreted with caution.

\section{TCF7L2}

Transcription factor 7-like 2 is a transcription factor expressed in $\mathrm{T}$ cells containing a high mobility group box that is thought to be involved in glucose homoeostasis. ${ }^{9}$ Musso et $a l^{81}$ investigated the rs7903146 variant of the TCF $7 L 2$ gene on an Italian population. A total of 78 patients with NAFLD, 34 of whom were biopsied and diagnosed with NASH, were compared with 156 healthy 
population controls. It was found that the wild type genotype was less frequent in patients with NAFLD compared with controls. The study reports that severe hepatic steatosis was predicted by TCF (OR 2.2, CI 1.7 to 4.9 ) and grade 3 fibrosis was predicted by TCF (OR 2.0, CI 1.7 to 4.3); however, the analysis of histological characteristics is limited due to small sample size and because all patients had NASH.

\section{Neurological}

The cannabinoid receptors are $\mathrm{G}$ protein coupled receptors expressed in the brain that mediate the neurological effects of cannabinoid substances through inhibition of adenylyl cyclase when activated. ${ }^{9}$ The NCAN gene on chromosome 19 encodes the core protein of neurocan, a chondroitin sulfate proteoglycan component of the extracellular matrix, primarily expressed in the nervous system and considered to be involved in cell adhesion and migration. ${ }^{9} 23$

\section{Cannabinoid receptor}

Aller $e t a b^{82}$ evaluated the influence of the cannabinoid receptor 1 gene rs1049353 variant on histological features of NAFLD on a cohort of 70 Spanish patients. The study found that significantly fewer patients with the variant $\mathrm{A}$ allele had histological grade of 4 or more, when compared with homozygous wild type patients, but fibrosis was not significantly different.

Rossi $e t a l^{83}$ investigated the effect of the Q63R variant of cannabinoid receptor 2 on histological severity of NAFLD in a cohort of 118 paediatric Italian patients. The variant was found to be strongly associated with degree of inflammation, but not with other histological characteristics of steatosis, fibrosis or ballooning. However, the relationship with inflammation was not significant after adjusting for the PNPLA3 variant, which had previously been shown to be significant in this cohort. ${ }^{16}$

\section{NCAN}

Gorden et $a t^{23}$ studied a cohort of 1092 US patients undergoing bariatric surgery, as described above. The variant in NCAN was significantly associated with increased histological features of steatosis, lobular inflammation and perivenular fibrosis, and trended towards increased ballooning. However, it is unclear whether these associations are independent of the association with the PNPLA3 rs738409 shown to be significantly associated with steatosis and ballooning in the same study.

\section{Miscellaneous TM6SF2}

TM6SF2 encodes a transmembrane protein of unknown function $;{ }^{9}$ the rs58542926 SNP in TM6SF2 is in strong linkage disequilibrium with the rs2228603 NCAN variant discussed above, and associations attributed to NCAN may relate instead to this variant. ${ }^{84}$
Liu $e t a l^{4}$ studied the effect of the rs58542926 variant of TM6SF2 on two cohorts with histologically characterised NAFLD. Quantitative analysis was performed within a discovery cohort of 349 UK patients with NAFLD, and results were validated using a cohort of 725 European Caucasian patients. Within the NAFLD discovery cohort, minor allele was significantly more frequent than the reference population, OR 1.72 (CI 1.16 to 2.57) and OR 4.84 (CI 1.01 to 22.9) for heterozygous and homozygous variants, respectively, when compared with healthy control group $(\mathrm{n}=379)$.

Histological characteristics were further investigated: degree of steatosis was not significantly associated with either rs2228603 in NCAN or rs58542926 in TM6SF2, in either cohort, although a trend was observed when the cohorts were combined. The authors suggest a possible relationship with a small effect size, which was supported by an association which was noted when the combined group was categorised into mild or pronounced steatosis. Severity of steatohepatits, assessed by characteristics of necroinflammation and hepatocyte ballooning, was associated with the TM6SF2 variant within the discovery cohort, but was not replicated in the validation or combined cohorts.

Importantly, the variants of $N C A N$ and TM6SF2 were both significantly associated with the stage of histological fibrosis. On further investigation, conditioning the results on TM6SF2 negated the effect of the NCAN variant, indicating TM6SF2 was responsible for the association relationship. This relationship was replicated in the validation and combined cohorts, and was independent of confounding factors including age, gender, BMI, presence of diabetes and PNPLA3 phenotype. When mild fibrosis was compared with advanced fibrosis in the combined cohort, each minor allele was associated with OR 1.88 (CI 1.41 to 2.50). The study also compared 99 UK patients with NAFLD-related HCC to the combined cohort. Although the homozygous variant of TM6SF2 was found associated with an increased risk of HCC in univariate analysis, this did not persist in multivariate analysis adjusted for confounding factors.

Since this study, two other studies have investigated the role of this polymorphism on histologically proven NAFLD: Dongiovanni $e t a l^{85}$ studied a large, combined cohort of adult and paediatric European patients undergoing liver biopsy for hepatology or bariatric purposes. Of these, 112 patients had no fatty liver disease and served as the control group, 412 had SS and 677 fulfilled histological NASH diagnosis. The results showed the variant to be associated with severity of all histological characteristics (steatosis, necroinflammation, ballooning and fibrosis stage), and this persisted after adjustment for age, gender, BMI, diabetes, recruitment and PNPLA3 genotype. The variant was associated with NASH compared with SS (OR 1.84, CI 1.23 to 2.79) and stage 3-4 fibrosis (OR 2.08, CI 1.20 to 3.55), although association with fibrosis did not remain after adjustment for NASH. 
Sookoian $e t a l^{86}$ performed a case-control study investigating the role of on TM6SF2 in an Argentinian population of 226 patients with histological NAFLD. In comparison to a control group of 135 individuals with no ultrasonographic evidence of fatty liver, the rs58542926 variant was found to be significantly associated with fatty liver (OR 1.37, CI 1.02 to 1.84); however, this relationship did not persist after adjusting for age, BMI and rs738409 in PNPLA3. The NAFLD group was subdivided into 96 patients with SS and 130 with NASH; the T allele was found to be associated with disease progression when the control group was included in the analysis; however, this was not significant when the SS group was compared with NASH. Within the patients with NAFLD, degree of steatosis was found to be significantly associated with this variant, independently of PNPLA3 genotype, age, sex and BMI. In contrast, no associations were observed with other histological characteristics of lobular inflammation, ballooning or fibrosis stage (F1-2 vs F3-4), and there was no association with increased NAS (defined as $>5$ ).

\section{SPINK1}

The SPINK 1 gene encodes serine peptidase inhibitor, Kazal type $1 .^{9}$ This enzyme inhibits trypsin, and is a component of pancreatic juice, secreted by pancreatic acinar cells; mutations result in familial calcific pancreatitis. ${ }^{9}$ Oruc et $a l^{87}$ evaluated the SPINK1 N34S P555 polymorphism in 50 Turkish patients with NAFLD and 44 controls. Of the NAFLD group, 30 patients had SS and 20 had NASH. No significant association was found between the SPINK1 variant with NAFLD or histological NASH.

\section{$A B C B 11$ and NR1H4}

Both the $A B C B 11$ and NR1H4 genes encode proteins involved in bile processing: ATP binding cassette transporter encoded by $A B C B 11$ is a membrane-bound transport protein that exports of bile salts into canaliculi, whereas NR1H4 encodes a nuclear receptor activated by bile acids that regulates their synthesis and transport. ${ }^{9}$ Iwata $e t a l^{88}$ evaluated the $A B C B 11$ 1331C allele and NRIH4 variants, comparing UK patients-358 with NAFLD, 206 with chronic hepatitis $\mathrm{C}$ and 110 controls undergoing biopsy for metastatic disease. There was no association found with NAFLD or fibrosis for either gene.

\section{CYP2E1 and NR112}

CYP2E1 encodes a cytochrome P450 enzyme involved in metabolism of endogenous and exogenous compounds, and NR1I2 encodes the pregnane $\mathrm{X}$ receptor, a transcriptional regulator of CYP $3 A 44^{9}$

Varela $e$ e $a l^{89}$ studied cytochrome P450 2E1 variants on 48 obese Chilean women undergoing bariatric surgery. Patients were biopsied and assessed: 15 were diagnosed with NASH, 17 had SS and 13 were histologically normal. The CYP4502E1 polymorphisms Dra1 and
Ras1/Pst1 were investigated and it was found that the heterozygous and homozygous variant genotypes of Dral increased the risk of both NASH and steatosis when compared with control. The Rsa/Pst variant genotypes also increased the risk of NASH compared with control, although it should be noted that the sample sizes utilised in this study were small.

Sookoian et a ${ }^{00}$ explored eight SNPs associated with NR1I2; only rs7643645 was significantly associated with NAFLD compared with control, with a recessive model for the homozygous variant with OR 3.292 (CI 1.398 to 7.752). Of 188 patients with NAFLD, 113 underwent liver biopsy; 46 had SS and 67 had NASH. Participants were divided into control, fatty liver with normal LFTs, SS and NASH groups to investigate disease severity, noting associations with rs7643645 and rs2461823.

\section{FABP2 and SLC27A5}

The fatty acid-binding protein 2 and fatty acid transport protein 5, encoded by FABP2 and SLC27A5, respectively, are involved in transport and processing of long chain fatty acids. ${ }^{9}$ Auinger $e t a \ell^{11}$ explored the rs56225452 variant of FATP5 (SLC27A5) on a cohort of 103 male patients with NAFLD. No difference between genotypes was observed in features of steatosis, fibrosis or necroinflammatory grade, although an association was observed with steatosis degree and BMI within variant allele carriers. Aller et $a \ell^{92}$ evaluated the effect of ala54thr of $F A B P 2$ on 30 patients with NAFLD, but no differences between histological features were observed.

\section{Genome-wide association studies}

GWASs aim to identify genetic susceptibility components that might predispose individuals to developing NAFLD and NASH. A total of five reports of GWASs have been performed on the NASH CRN and Japanese populations.

Chalasani et a ${ }^{\rho 3}$ performed a GWAS analysing 324623 SNPs on 236 female patients in the US NASH CRN cohort, diagnosed using the NASH CRN scoring system. Results showed that FDFT1 variant rs2645424 was associated with NAS, fibrosis was associated with rs343062 on chromosome 7 , and lobular inflammation was associated with SNPs in LTBP3, EFCAB4B and COLI3A1.

Speliotes $e$ t $a \ell^{4}$ performed primary GWAS testing on a large cohort of patients with CT assessed NAFLD, from which 46 SNPs were selected for further analysis in patients with histologically determined NAFLD. A total of 592 patients within the NASH CRN cohort were compared with 1405 US and European healthy patients enrolled in the MIGen study. The rs738409 in PNPLA3 and rs2228603 in NCAN were found to be significantly associated with histological NAFLD, with ORs of 3.26 and 1.65 , respectively. The rs4240624 in PPP1R3B was not associated with histological NAFLD; however, rs780094 in GCKR (OR 1.45) and rs12137855 near LYPLAL1 (OR 1.37) were also significantly associated with NAFLD. The MIGen cohort was used to control for cardiovascular disease status. Therefore, to ensure that 
the use of this control group was not influential, the five variants (PNPLA3, NCAN, GCKR, LYLPAL1 and $P P P 1 R 3 B)$ were compared between the NASH CRN cohort and 3212 healthy participants within the Illuminata Control Database (iCONT). The results of this were comparable to those from the NASH CRN/ MIGen comparison.

Kawaguchi et $a l^{11}$ performed a GWAS of 484751 SNPs plus PNPLA3 rs738409 on a Japanese population. Initially, 529 patients with NAFLD were compared with 942 healthy controls, and significance was observed for six markers in PNPLA3 including rs738409, which demonstrated the strongest association. The NAFLD group was further divided into four subgroups based on histological class, and genotype distributions were analysed in a pairwise manner. Matteoni ${ }^{95}$ class 4 was found to be significantly different from the other three subgroups, and associated with the rs738409 variant. Histological characteristics of Brunt grade and stage, ${ }^{96}$ fat deposition, iron deposition were associated with the variant $\mathrm{G}$ allele; however, of these only iron deposition remained significant after Bonferroni correction and adjustment for Matteoni type. The authors propose that NASH (assessed as Matteoni type 4) is a clinically and genetically different condition. Of the other polymorphisms investigated, no association was seen with variants in LYPLAL1 or NCAN genes, but rs780094 in GCKR showed borderline association.

Kitamoto et $a \ell^{97}$ performed a pilot GWAS on 392 Japanese patients with NAFLD (345 NASH, 47 SS). Initially, 261540 genes were analysed and compared with a group of 934 healthy controls. Subsequently, 56 SNPs were further analysed in a replication study, comprised of 172 patients with NAFLD (97 NASH, 4 SS, 71 not biopsied) and 1012 healthy controls. Following the replication study, 12 SNPs remained significantly associated following the replication study, and of these, 8 retained significance after conservative Bonferroni correction. These 8 SNPs were all variants close to PNPLA3 on chromosome 22, and did not retain significance after rs738409 was accounted for, and haplotype analysis suggested that PNPLA3 was significantly associated with NAFLD pathogenesis. When histological characteristics were assessed, six polymorphisms were associated with histological fibrosis, and nine were associated with lobular inflammation, hepatocyte ballooning and NAS, but these were not significant after correction for multiple testing. When NASH patients were compared with those with SS, the rs5764455 variant in PARVB was associated with NASH (OR 2.79).

Vazquez-Chantada et a ${ }^{\rho 8}$ extracted DNA from liver biopsy samples and tested 92 genes for association with NAFLD in a Spanish pilot study of 69 patients with NAFLD and 217 controls. In total, 1536 SNPs were selected for further analysis and 11 SNPs were found to be associated with NAFLD, 7 of these in the SLC2A1 gene and 1 close to $S L C 2 A 1$, and variants in CYP2E1, $M T R$ and STK11. A validation study was then performed on a cohort of 451 European patients with NAFLD and 303 controls, and confirmed that rs4658 and rs841856 in SLC2A1 were significantly more frequent in the NAFLD group, however no association was seen in the other variants. The study found no significant association with clinical characteristics of NAFLD.

\section{CONCLUSION}

Variants in many genes have been investigated for association with NAFLD and with histological characteristics and progression to NASH. Of the genes studied, many could have plausible mechanistic roles in NAFLD and NASH pathogenicity, for example, in profibrogenic and inflammatory pathways, regulation of energy, metabolism and lipid processing. Other genes investigated are those that have potential roles in obesity, hypertension and dyslipidaemias.

Only six genes described in this review have been replicated in more than one histologically characterised cohort: PNPLA3, APOE, SOD2, TNF, TM6SF2 and GCKR (highlighted in table 1). The main, consistent finding of the candidate gene studies is the association of PNPLA3 rs738409 variant with NAFLD susceptibility. Results regarding the association of this polymorphism with histological characteristics and disease severity are inconsistent.

Differences may be due to patient characteristics including environment or ancestry, with findings and the strength of associations differing between populations. Even within a biopsy proven cohort, there are further confounding factors of age, sex, BMI, comorbidities including diabetes, diet, exercise and medication to consider. Methodological factors including the size of patient cohorts and control population(s), the method and criteria used for histological assessment, which are not necessarily comparable, and statistical handling of data may also account for discrepancies.

Liver biopsy is an invasive procedure that can involve complications of infection, haemorrhage and an approximate $1 / 10000$ mortality. ${ }^{99}$ Therefore, larger cohorts of biopsied patients, such as the NASH CRN, Malaysian cohort and the Italian and UK groups have been used in multiple investigations, which needs to be borne in mind when considering effects of marginal significance.

Various study designs were used to address differing putative gene effects, studies comparing patient cohorts to healthy control groups were used to assess for genetic association with disease. Severity of histological characteristics were compared within patient cohorts, and some studies used control groups with other causes of hepatic fibrosis, such as alcoholic liver disease or hepatitis $\mathrm{C}$ to determine whether genetic factors influencing fibrosis were specific to NASH or related to common pathways of fibrosis. It may be that there are multiple genetic factors that come into play, with separate groups of genes influencing NAFLD susceptibility, 
and different molecular pathways involved steatosis, inflammation and fibrosis of disease progression.

In this review, methods for reporting results were restricted to individual genes; however, a novel method of reporting using PID pathways was utilised by Chen et $a t^{6}$ (not included in review), which may be useful to identify the molecular pathways involved in the development of NAFLD and progression to NASH. Similarly, as whole genome scanning becomes more time and cost efficient, it is likely that more studies will utilise this technique for investigating genetic factors of a disease.

This review has aimed to independently and systematically summarise the candidate gene studies relating to NAFLD and NASH. Fatty liver is a complex disease, with a spectrum of severity encompassing clinical features of steatosis, inflammation and fibrosis. Only a subgroup of patients with SS progresses to develop NASH and hepatic fibrosis. It is possible that there are multiple genetic components influencing susceptibility through distinct pathways, and that the interaction of these may cause disease progression.

Contributors KLW collected the data and prepared the manuscript. MHM and JFD supervised the study, providing guidance and feedback on the manuscript.

Competing interests None.

Provenance and peer review Not commissioned; externally peer reviewed.

Data sharing statement No additional data are available.

Open Access This is an Open Access article distributed in accordance with the terms of the Creative Commons Attribution (CC BY 4.0) license, which permits others to distribute, remix, adapt and build upon this work, for commercial use, provided the original work is properly cited. See: http:// creativecommons.org/licenses/by/4.0/

\section{REFERENCES}

1. LaBrecque D, Abbas Z, Anania F, et al. World Gastroenterology Organisation Global Guidelines. Nonalcoholic fatty liver disease and nonalcoholic steatohepatitis. Millwaukee, WI: World Gastroenterology Organisation, 2012.

2. British Society of Gastroenterology. Clinical. Commissioning Report. Chronic management. NASH and non-alcoholic fatty liver disease. Secondary Clinical. Commissioning Report. Chronic management. NASH and non-alcoholic fatty liver disease c2009. http://www.bsg.org.uk/clinical/commissioning-report/nash-and-nonalcoholic-fatty-liver-disease.html

3. Kleiner DE, Brunt EM, Van Natta M, et al. Design and validation of a histological scoring system for nonalcoholic fatty liver disease. Hepatology 2005;41:1313-21.

4. Moher D, Liberati A, Tetzlaff J, et al:; The PRISMA Group. Preferred reporting items for systematic reviews and meta-analyses: the PRISMA statement. PLoS Med 2009;6: e1000097

5. Musso G, Gambino R, De Michieli F, et al. Adiponectin gene polymorphisms modulate acute adiponectin response to dietary fat: Possible pathogenetic role in NASH. Hepatology 2008;47:1167-77.

6. Chen Q-R, Braun R, Hu Y, et al. Multi-SNP analysis of GWAS data identifies pathways associated with nonalcoholic fatty liver disease. PLOS ONE 2013;8:e65982.

7. de Alwis N, Aithal G, Bugianesi E, et al. Mitochondrial DNA does not contribute to the heritability of non-alcoholic fatty liver disease. Mitochondrion 2011;11:234-5.

8. Gerhard GS, Chu X, Wood GC, et al. Next-generation sequence analysis of genes associated with obesity and nonalcoholic fatty liver disease-related cirrhosis in extreme obesity. Hum Hered 2013;75:144-51.

9. GeneCards Human Gene Database. Secondary GeneCards Human Gene Database c2014. http://www.genecards.org
10. Romeo S, Kozlitina J, Xing C, et al. Genetic variation in PNPLA3 confers susceptibility to nonalcoholic fatty liver disease. Nat Genet 2008;40:1461-5.

11. Kawaguchi T, Sumida Y, Umemura A, et al. Genetic polymorphisms of the human PNPLA3 gene are strongly associated with severity of non-alcoholic fatty liver disease in Japanese. PLoS ONE 2012;7(6):e38322.

12. Sookoian $\mathrm{S}$, Castaño $\mathrm{GO}$, Burgueño $\mathrm{AL}$, et al. A nonsynonymous gene variant in the adiponutrin gene is associated with nonalcoholic fatty liver disease severity. J Lipid Res 2009;50:2111-16.

13. Hotta K, Yoneda M, Hyogo H, et al. Association of the rs738409 polymorphism in PNPLA3 with liver damage and the development of nonalcoholic fatty liver disease. BMC Med Genet 2010;11:172-2.

14. Zain SM, Mohamed R, Mahadeva S, et al. A multi-ethnic study of a PNPLA3 gene variant and its association with disease severity in non-alcoholic fatty liver disease. Hum Genet 2012;131:1145-52.

15. Valenti L, Al-Serri A, Daly AK, et al. Homozygosity for the patatin-like phospholipase-3/adiponutrin I148M polymorphism influences liver fibrosis in patients with nonalcoholic fatty liver disease. Hepatology 2010;51:1209-17.

16. Valenti L, Alisi A, Galmozzi E, et al. I148M patatin-like phospholipase domain-containing 3 gene variant and severity of pediatric nonalcoholic fatty liver disease. Hepatology 2010;52 1274-80

17. Verrijken A, Beckers S, Francque $S$, et al. A gene variant of PNPLA3, but not of APOC3, is associated with histological parameters of NAFLD in an obese population. Obesity 2013;21:2138-45.

18. Guichelaar MMJ, Gawrieh S, Olivier M, et al. Interactions of allelic variance of PNPLA3 with nongenetic factors in predicting nonalcoholic steatohepatitis and nonhepatic complications of severe obesity. Obesity 2013;21:1935-41.

19. Rotman Y, Koh C, Zmuda JM, et al. The association of genetic variability in patatin-like phospholipase domain-containing protein 3 (PNPLA3) with histological severity of nonalcoholic fatty liver disease. Hepatology 2010;52:894-903.

20. Speliotes EK, Butler JL, Palmer CD, et al. PNPLA3 variants specifically confer increased risk for histologic nonalcoholic fatty liver disease but not metabolic disease. Hepatology 2010;52:90412.

21. Petta S, Grimaudo S, Cammà C, et al. IL28B and PNPLA3 polymorphisms affect histological liver damage in patients with non-alcoholic fatty liver disease. J Hepatol 2012;56:1356-62.

22. Corbin KD, Abdelmalek MF, Spencer MD, et al. Genetic signatures in choline and 1-carbon metabolism are associated with the severity of hepatic steatosis. FASEB J 2013;27:1674-89.

23. Gorden A, Yang R, Yerges-Armstrong LM, et al. Genetic variation at NCAN locus is associated with inflammation and fibrosis in non-alcoholic fatty liver disease in morbid obesity. Hum Hered 2013;75:34-43.

24. Sookoian S, Pirola CJ. Meta-analysis of the influence of I148M variant of patatin-like phospholipase domain containing 3 gene (PNPLA3) on the susceptibility and histological severity of nonalcoholic fatty liver disease. Hepatology 2011;53:1883-94.

25. Valenti L, Motta BM, Alisi A, et al. LPIN1 rs13412852 polymorphism in pediatric nonalcoholic fatty liver disease. $J$ Pediatr Gastroenterol Nutr 2012;54:588-93.

26. Kersten S, Desvergne B, Wahli W. Roles of PPARs in health and disease. Nature 2000;405:421-4.

27. Gawrieh S, Marion MC, Komorowski R, et al. Genetic variation in the peroxisome proliferator activated receptor-gamma gene is associated with histologically advanced NAFLD. Dig Dis Sci 2012;57:952-7.

28. Rey J-W, Noetel A, Hardt A, et al. Pro12Ala polymorphism of the peroxisome proliferator-activated receptor $\gamma 2$ in patients with fatty liver diseases. World J Gastroenterol 2010;16:5830-7.

28a. Dongiovanni P, Rametta R, Fracanzani AL, et al. Lack of association between peroxisome proliferator-activated receptors alpha and gamma2 polymorphisms and progressive liver damage in patients with non-alcoholic fatty liver disease: a case control study. BMC Gastroenterology 2010;10:102-8.

29. Domenici FA, Brochado MJF, Martinelli Ade LC, et al. Peroxisome proliferator-activated receptors alpha and gamma2 polymorphisms in nonalcoholic fatty liver disease: a study in Brazilian patients. Gene 2013;529:326-31.

30. Yoneda M, Hotta K, Nozaki Y, et al. Association between PPARGC1A polymorphisms and the occurrence of nonalcoholic fatty liver disease (NAFLD). BMC Gastroenterol 2008;8:27.

31. Sahebkar A. Does PPAR 2 gene Pro12Ala polymorphism affect nonalcoholic fatty liver disease risk? Evidence from a meta-analysis. DNA Cell Biol 2013;32:188-98. 
32. Valenti L, Nobili V, Al-Serri A, et al. The APOC3 T-455C and $\mathrm{C}-482 \mathrm{~T}$ promoter region polymorphisms are not associated with the severity of liver damage independently of PNPLA3 I148M genotype in patients with nonalcoholic fatty liver. $J$ Hepatol 2011;55:1409-14.

33. Sazci A, Akpinar G, Aygun C, et al. Association of apolipoprotein E polymorphisms in patients with non-alcoholic steatohepatitis. Dig Dis Sci 2008:53:3218-24.

34. De Feo E, Cefalo C, Arzani D, et al. A case-control study on the effects of the apolipoprotein $\mathrm{E}$ genotypes in nonalcoholic fatty liver disease. Mol Biol Rep 2012;39:7381-8.

35. Gambino R, Cassader M, Pagano G, et al. Polymorphism in microsomal triglyceride transfer protein: a link between liver disease and atherogenic postprandial lipid profile in NASH? Hepatology 2007;45:1097-107.

36. Musso G, Cassader M, De Michieli F, et al. Effect of lectin-like oxidized LDL receptor-1 polymorphism on liver disease, glucose homeostasis, and postprandial lipoprotein metabolism in nonalcoholic steatohepatitis. Am J Clin Nutr 2011;94:1033-42.

37. Dong $\mathrm{H}$, Wang J, Li C, et al. The phosphatidylethanolamine $\mathrm{N}$-methyltransferase gene V175M single nucleotide polymorphism confers the susceptibility to NASH in Japanese population. $J$ Hepatol 2007:46:915-20.

38. Namikawa C, Shu-Ping Z, Vyselaar JR, et al. Polymorphisms of microsomal triglyceride transfer protein gene and manganese superoxide dismutase gene in non-alcoholic steatohepatitis. $J$ Hepatol 2004;40:781-6.

39. Carulli L, Canedi I, Rondinella S, et al. Genetic polymorphisms in non-alcoholic fatty liver disease: interleukin-6-174G/C polymorphism is associated with non-alcoholic steatohepatitis. Dig Liver Dis 2009;41:823-8.

40. Oliveira CPMS, Stefano JT, Cavaleiro AM, et al. Association of polymorphisms of glutamate-cystein ligase and microsomal triglyceride transfer protein genes in non-alcoholic fatty liver disease. J Gastroenterol Hepatol 2010;25:357-61.

41. El-Koofy NM, El-Karaksy HM, Mandour IM, et al. Genetic polymorphisms in non-alcoholic fatty liver disease in obese Egyptian children. Saudi J Gastroenterol 2011;17:265-70.

42. Musso G, Bo S, Cassader M, et al. Impact of sterol regulatory element-binding factor-1c polymorphism on incidence of nonalcoholic fatty liver disease and on the severity of liver disease and of glucose and lipid dysmetabolism. Am J Clin Nutr 2013:98:895-906.

43. Musso G, Cassader M, Bo S, et al. Sterol regulatory element-binding factor 2 (SREBF-2) predicts 7-year NAFLD incidence and severity of liver disease and lipoprotein and glucose dysmetabolism. Diabetes 2013;62:1109-20.

44. Al-Serri A, Anstee QM, Valenti L, et al. The SOD2 C47T polymorphism influences NAFLD fibrosis severity: evidence from case-control and intra-familial allele association studies. $J$ Hepatol 2012;56:448-54

45. Aller R, De Luis DA, Izaola O, et al. Role of -55CT polymorphism of UCP3 gene on non alcoholic fatty liver disease and insulin resistance in patients with obesity. Nutr Hosp 2010;25:572-6.

46. Lu SC. Glutathione synthesis. Biochim Biophys Acta 2013;1830: 3143-53.

47. Valenti L, Fracanzani AL, Dongiovanni $\mathrm{P}$, et al. Tumor necrosis factor alpha promoter polymorphisms and insulin resistance in nonalcoholic fatty liver disease. Gastroenterology 2002;122:274-80.

48. Yang HR, Ko JS, Seo JK. Role of tumor necrosis factor- $\alpha$ promoter polymorphism and insulin resistance in the development of non-alcoholic fatty liver disease in obese children. Paediatr Gastroenterol Hepatol Nutr 2012;15:44-51.

49. Hu Z-W, Luo H-B, Xu Y-M, et al. Tumor necrosis factor-alpha gene promoter polymorphisms in Chinese patients with nonalcoholic fatty liver diseases. Acta Gastroenterol Belg 2009;72:215-21.

50. Chowdhury SD, Ramakrishna B, Eapen CE, et al. Fibrosis in non-alcoholic fatty liver disease: correlation with simple blood indices and association with tumor necrosis factor-alpha polymorphisms. Trop Gastroenterol 2013;34:31-5.

51. Aller $\mathrm{R}$, de Luis DA, Izaola O, et al. G308A polymorphism of TNF-alpha gene is associated with insulin resistance and histological changes in non alcoholic fatty liver disease patients. Ann Hepatol 2010;9:439-44.

52. Tokushige K, Takakura M, Tsuchiya-Matsushita N, et al. Influence of TNF gene polymorphisms in Japanese patients with NASH and simple steatosis. J Hepatol 2007;46:1104-10.

53. Wong VW-S, Wong GL-H, Tsang SW-C, et al. Genetic polymorphisms of adiponectin and tumor necrosis factor-alpha and nonalcoholic fatty liver disease in Chinese people. J Gastroenterol Hepatol 2008;23:914-21.
54. Nozaki Y, Saibara T, Nemoto Y, et al. Polymorphisms of interleukin-1 beta and beta 3-adrenergic receptor in Japanese patients with nonalcoholic steatohepatitis. Alcohol Clin Exp Res 2004;28(8 Suppl Proceedings):106S-10S.

55. Akyildiz M, Gunsar F, Nart D, et al. Macrophage migration inhibitory factor expression and MIF gene $-173 \mathrm{G} / \mathrm{C}$ polymorphism in nonalcoholic fatty liver disease. Eur J Gastroenterol Hepatol 2010;22:192-8.

56. Brun $\mathrm{P}$, Castagliuolo I, Floreani AR, et al. Increased risk of NASH in patients carrying the $\mathrm{C}(-159) \mathrm{T}$ polymorphism in the CD14 gene promoter region. Gut 2006;55:1212.

57. Tokushige $\mathrm{K}$, Hashimoto $\mathrm{E}$, Noto $\mathrm{H}$, et al. Influence of adiponectin gene polymorphisms in Japanese patients with non-alcoholic fatty liver disease. J Gastroenterol 2009;44:976-82.

58. Gupta AC, Misra R, Sakhuja $P$, et al. Association of adiponectin gene functional polymorphisms $(-11377 \mathrm{C} / \mathrm{G}$ and $+45 \mathrm{~T} / \mathrm{G})$ with nonalcoholic fatty liver disease. Gene 2012;496:63-7.

59. Zain SM, Mohamed Z, Mahadeva S, et al. Impact of leptin receptor gene variants on risk of non-alcoholic fatty liver disease and its interaction with adiponutrin gene. J Gastroenterol Hepatol 2013;28:873-9.

60. Aller R, De Luis DA, Izaola O, et al. Lys656Asn polymorphism of leptin receptor, leptin levels and insulin resistance in patients with non alcoholic fatty liver disease. Eur Rev Med Pharmacol 2012:16:335-41.

61. Swellam M, Hamdy N. Association of nonalcoholic fatty liver disease with a single nucleotide polymorphism on the gene encoding leptin receptor. IUBMB Life 2012;64:180-6.

62. Sookoian S, Castaño G, Gianotti TF, et al. Genetic variants in STAT3 are associated with nonalcoholic fatty liver disease. Cytokine 2008;44:201-6.

63. Sookoian S, Castaño G, Gemma C, et al. Common genetic variations in CLOCK transcription factor are associated with nonalcoholic fatty liver disease. World J Gastroenterol 2007;13:4242-8.

64. Sazci A, Ergul E, Aygun C, et al. Methylenetetrahydrofolate reductase gene polymorphisms in patients with nonalcoholic steatohepatitis (NASH). Cell Biochem Funct 2008;26:291-6.

65. Serin $\mathrm{E}$, Güçlü $\mathrm{M}$, Ataç $\mathrm{FB}$, et al. Methylenetetrahydrofolate reductase C677T mutation and nonalcoholic fatty liver disease. Dig Dis Sci 2007;52:1183-6.

66. Assy N, Bekirov I, Mejritsky Y, et al. Association between thrombotic risk factors and extent of fibrosis in patients with non-alcoholic fatty liver diseases. World J Gastroenterol 2005;11:5834-9.

67. Miele L, Beale G, Patman G, et al. The Kruppel-like factor 6 genotype is associated with fibrosis in nonalcoholic fatty liver disease. Gastroenterology 2008;135:282-91.e1.

68. Valenti L, Dongiovanni $\mathrm{P}$, Fracanzani AL, et al. Increased susceptibility to nonalcoholic fatty liver disease in heterozygotes for the mutation responsible for hereditary hemochromatosis. Dig Liver Dis 2003;35:172-8.

69. Valenti L, Fracanzani AL, Bugianesi E, et al. HFE genotype, parenchymal iron accumulation, and liver fibrosis in patients with nonalcoholic fatty liver disease. Gastroenterology 2010;138:90512.

70. Deguti MM, Sipahi AM, Gayotto LCC, et al. Lack of evidence for the pathogenic role of iron and HFE gene mutations in Brazilian patients with nonalcoholic steatohepatitis. Braz J Med Biol Res 2003:36:739-45.

71. Zamin I, Mattos AA, Mattos AZ, et al. Prevalence of the hemochromatosis gene mutation in patients with nonalcoholic steatohepatitis and correlation with degree of liver fibrosis. Arq Gastroenterol 2006;43:224-8.

72. Raszeja-Wyszomirska J, Kurzawski G, Lawniczak M, et al. Nonalcoholic fatty liver disease and HFE gene mutations: a Polish study. World J Gastroenterol 2010;16:2531-6.

73. Nelson JE, Brunt EM, Kowdley KV. Lower serum hepcidin and greater parenchymal iron in nonalcoholic fatty liver disease patients with C282Y HFE mutations. Hepatology 2012;56: 1730-40.

74. Valenti L, Rametta R, Dongiovanni P, et al. The A736V TMPRSS6 polymorphism influences hepatic iron overload in nonalcoholic fatty liver disease. PLoS ONE 2012; 7:e48804-.

75. Zain SM, Mohamed Z, Mahadeva S, et al. Susceptibility and gene interaction study of the angiotensin II type 1 receptor (AGTR1) gene polymorphisms with non-alcoholic fatty liver disease in a multi-ethnic population. PLOS ONE 2013;8:e58538

76. Dixon JB, Bhathal PS, Jonsson JR, et al. Pro-fibrotic polymorphisms predictive of advanced liver fibrosis in the severely obese. J Hepatol 2003;39:967-71. 
77. Yoneda M, Hotta K, Nozaki Y, et al. Association between angiotensin II type 1 receptor polymorphisms and the occurrence of nonalcoholic fatty liver disease. Liver Int 2009;29:1078-85.

78. Espino A, Villagrán A, Vollrath V, et al. Plasminogen activator inhibitor type 1 serum levels and $4 \mathrm{G} / 5 \mathrm{G}$ gene polymorphism in morbidly obese Hispanic patients with non-alcoholic fatty liver disease. Ann Hepatol 2011;10:493-501.

79. Dongiovanni $P$, Valenti L, Rametta R, et al. Genetic variants regulating insulin receptor signalling are associated with the severity of liver damage in patients with non-alcoholic fatty liver disease. Gut 2010;59:267-73.

80. Tan HL, Zain SM, Mohamed R, et al. Association of glucokinase regulatory gene polymorphisms with risk and severity of non-alcoholic fatty liver disease: an interaction study with adiponutrin gene. J Gastroenterol 2014;49:1056-64.

81. Musso G, Gambino R, Pacini G, et al. Transcription factor 7-like 2 polymorphism modulates glucose and lipid homeostasis, adipokine profile, and hepatocyte apoptosis in NASH. Hepatology 2009;49:426-35.

82. Aller R, de Luis DA, Pacheco D, et al. Influence of G1359A polimorphysm of the cannabinoid receptor gene (CNR1) on insulin resistance and adipokines in patients with non alcoholic fatty liver disease. Nutr Hosp 2012;27:1637-42.

83. Rossi F, Bellini G, Alisi A, et al. Cannabinoid receptor type 2 functional variant influences liver damage in children with non-alcoholic fatty liver disease. PLOS ONE 2012;7:e42259.

84. Liu YL, Reeves HL, Burt AD, et al. TM6SF2 rs58542926 influences hepatic fibrosis progression in patients with non-alcoholic fatty liver disease. Nat Commun 2014;5:4309.

85. Dongiovanni P, Petta S, Maglio C, et al. TM6SF2 gene variant disentangles nonalcoholic steatohepatitis from cardiovascular disease. Hepatology 2015;61:506-14.

86. Sookoian S, Castano GO, Scian R, et al. Genetic variation in transmembrane 6 superfamily member 2 and the risk of nonalcoholic fatty liver disease and histological disease severity. Hepatology 2015;61:515-25.

87. Oruc N, Ozutemiz O, Berdeli A, et al. Common SPINK-1 mutations do not predispose to the development of non-alcoholic fatty liver disease. Ann Hepatol 2009;8:116-19.

88. Iwata R, Baur K, Stieger B, et al. A common polymorphism in the ABCB11 gene is associated with advanced fibrosis in hepatitis $C$ but not in non-alcoholic fatty liver disease. Clin Sci 2011;120:287-96.
89. Varela NM, Quiñones LA, Orellana M et al. Study of cytochrome P450 2E1 and its allele variants in liver injury of nondiabetic, nonalcoholic steatohepatitis obese women. Biol Res 2008;41:81-92.

90. Sookoian S, Castaño GO, Burgueño AL, et al. The nuclear receptor PXR gene variants are associated with liver injury in nonalcoholic fatty liver disease. Pharmacogenet Genomics 2010;20:1-8.

91. Auinger A, Valenti L, Pfeuffer $\mathrm{M}$, et al. A promoter polymorphism in the liver-specific fatty acid transport protein 5 is associated with features of the metabolic syndrome and steatosis. Horm Metab Res 2010;42:854-9.

92. Aller R, De Luis DA, Fernandez L, et al. Influence of Ala54Thr polymorphism of fatty acid-binding protein 2 on histological alterations and insulin resistance of non alcoholic fatty liver disease. Eur Rev Med Pharmacol 2009;13:357-64.

93. Chalasani N, Guo X, Loomba R, et al. Genome-wide association study identifies variants associated with histologic features of nonalcoholic Fatty liver disease. Gastroenterology 2010;139:1567.

94. Speliotes EK, Yerges-Armstrong LM, Wu J, et al. Genome-wide association analysis identifies variants associated with nonalcoholic fatty liver disease that have distinct effects on metabolic traits. PLoS Genet 2011;7:e1001324.

95. Matteoni CA, Younossi ZM, Gramlich T, et al. Nonalcoholic fatty liver disease: a spectrum of clinical and pathological severity. Gastroenterology 1999;116:1413-19.

96. Brunt EM, Janney CG, Di Bisceglie AM, et al. Nonalcoholic steatohepatitis: a proposal for grading and staging the histological lesions. Am J Gastroenterol 1999;94:2467-74.

97. Kitamoto T, Kitamoto A, Yoneda M, et al. Genome-wide scan revealed that polymorphisms in the PNPLA3, SAMM50, and PARVB genes are associated with development and progression of nonalcoholic fatty liver disease in Japan. Hum Genet 2013;132:783-92.

98. Vazquez-Chantada M, Gonzalez-Lahera A, Martinez-Arranz I, et al. Solute carrier family 2 member 1 is involved in the development of nonalcoholic fatty liver disease. Hepatology 2013;57:505-14.

99. Howlett DC, Drinkwater KJ, Lawrence D, et al. Findings of the UK national audit evaluating image-guided or image-assisted liver biopsy. Part II. Minor and major complications and procedure-related mortality. Radiology 2013;266:226-35. 